\title{
El retorno más allá del mito del emprendedor. Estrategias económicas, familiares y afectivas de mujeres y hombres a su regreso a Ecuador desde España
}

\author{
Cristina Vega \\ Facultad Latinoamericana de Ciencias Sociales \\ cregas@flacso.edu.ec
}

Recibido: 21-11-2014

Aceptado: 11-04-2016

\section{Resumen}

El artículo analiza las estrategias que pone en marcha un grupo de ecuatorianos y ecuatorianas a su regreso al Ecuador tras una década en España. Se trata del grupo de perceptores del Fondo Cucayo del Estado ecuatoriano, una política pública dirigida a la inserción sociolaboral a través del emprendimiento gestionada por la Secretaría Nacional del Migrante (SENAMI) entre 2008 y 2012. Se da cuenta de la manera en que dicha política ha de entenderse en un contexto de cambios puntuado por la crisis económica en España y las reformas políticas, económicas y sociales en Ecuador. A partir de un estudio cualitativo con entrevistas a miembros de distintas familias en Ecuador y España, se discute, desde una perspectiva de género y generación, la centralidad del emprendimiento en la puesta en marcha de estrategias por parte de los retornados. Se argumenta que los pequeños negocios abiertos por estos no son el determinante en los procesos de retorno. La estrategia de emprender un negocio, con o sin ayuda, se valora y se articula con otros aspectos de la vida diaria individual y familiar, entre los que destacan los afectivos, la organización social del cuidado, la formación de hijos e hijas e incluso otros proyectos de carácter laboral. Dicha articulación ha de ser analizada desde una perspectiva que contemple las dinámicas de clase, género y edad en los procesos migratorios, así como el modo en que estas se despliegan según la composición de la familia.

Palabras clave: migración de retorno; crisis; desarrollo; emprendimiento; género; estrategias familiares 
Abstract. Return Migration Beyond the Myth of the Entrepreneur: Women and Men's Economic, Family and Affective Strategies in Their Return to Ecuador from Spain

This paper analyzes the strategies carried out by a group of men and women upon their return to Ecuador after a migratory period of over a decade in Spain. These returning migrants are beneficiaries of the Cucayo subsidy provided by the Ecuadorian state in order to facilitate their self-employment. This public policy, managed by the National Secretary of Migration between 2008 and 2012, must be understood in the context of economic crisis in Spain and political, economic and social institutional reforms in Ecuador. A qualitative study based on interviews with members from families in both countries, analyzed from gender and generational perspectives, puts into question the central role of entrepreneurship in return processes. The promoted strategy of starting a business can only be understood when considered in conjunction with other individual and family aspects of migrants' experiences. These include affective ties, the organization of care, daughters and sons' education and other employment opportunities. The dynamic articulation of these elements in migration processes must take into account class, gender and age differences, as well as the composition of the family unit.

Keywords: return migration; crisis; development; entrepreneurship; gender; family strategies

\section{Sumario}

\section{Introducción}

2. Enfoques críticos sobre desarrollo, emprendimiento y "retorno productivo"

3. Aproximarse al retorno desde un enfoque transnacional de clase, género y generación

4. El retorno a Ecuador. Crisis y oportunidades
5. Metodología

6. Estrategias socioeconómicas, familiares y afectivas de los retornados. Mitos y realidades

7. Conclusiones

Referencias bibliográficas

\section{Introducción}

A menudo, tanto la migración como el retorno se han analizado como estrategias de reproducción social que se dirimen en el terreno estrictamente económico. De acuerdo con esta perspectiva, los migrantes son, por encima de todo, agentes económicos cuyo afán es maximizar las oportunidades. Cuando estas dejan de ser convenientes en destino, como sucede en un contexto de crisis económica y social como el que actualmente atraviesa España, el migrante propenderá a regresar a su país de origen, en el que será considerado un sujeto particularmente dinámico para el desarrollo. Este dinamismo, que en el pasado se centró en el envío de remesas, hoy descansa en la adecuada movilización del capital económico, pero también formativo, acumulado durante la migración, y su concreción en emprendimientos productivos. Así, aquellos que hayan sido capaces de ahorrar e invertir de forma adecuada habrán logrado poner las bases para generar un retorno autosustentable, algo positivamente valorado por los estados de destino. 
En Ecuador, esta percepción coincide con una coyuntura política en la que el Estado trata de romper con discursos anteriores sobre los migrantes recuperando la dignidad perdida de estos compatriotas, que, en adelante, reaparecerán en la imaginación política transnacional como encarnación del «exilio» neoliberal. De este modo, la política de «bienvenida a casa» se convierte en una forma de restituir una deuda en la historia reciente del país, así como de recuperar a los migrantes en el nuevo modelo de desarrollo de la nación. En este sentido, se han puesto en marcha programas cuyo objetivo es poner en juego el acumulado financiero, formativo y experiencial de los migrantes durante su estancia en el exterior. A pesar del reconocimiento de las dificultades que han afrontado al vivir «entre crisis y crisis» (Hernández et al., 2012), la imagen preponderante de los que hoy regresan aparece aún dominada por una idea eminentemente exitosa del tiempo que han pasado fuera y de las potencialidades que pueden brindar al país.

La hipótesis que se plantea es que, lejos de aglutinar sus expectativas en torno a las visiones de desarrollo que implican los emprendimientos y su potencial simbólico y económico, los migrantes regresan animados por una articulación compleja de motivos y estrategias que incluyen arreglos reproductivos y afectivos, formación de hijos, hijas y otros familiares o iniciativas laborales $\mathrm{y}$ financieras. Todo ello se dirime y ha de ser considerado en una perspectiva transnacional de género que sitúe las circunstancias que rodean la crisis socioeconómica en destino y las expectativa que emanan y se proyectan en origen. Más allá del emprendimiento el retorno incorpora un conjunto de respuestas que se articulan a distintos niveles.

Partiendo de esta hipótesis se analizan las motivaciones y las estrategias de un colectivo de emprendedores que regresan desde España: los que se acogieron entre 2008-2010 y 2010-2012 al Fondo Cucayo provisto por el Gobierno para empezar un negocio. Se presentan los resultados de parte de una investigación más extensa sobre estrategias en el retorno de los ecuatorianos residentes en España ${ }^{1}$. Aproximarse a este grupo permite entender a un sector de migrantes de clase media que cuentan, a pesar de sus diferencias internas y tras una media de diez años en España, con el capital económico y social necesario para iniciar un negocio a pesar de las afectaciones de la crisis.

Se muestra la trama compleja de motivaciones y estrategias vinculadas al género y a la generación que animan a estos actores respondiendo a algunas preguntas relevantes: ¿qué diferencias experimentan hombres y mujeres a la hora de regresar y reintegrarse a sus localidades de origen?, ¿qué priorizan en

1. Corresponde al proyecto El retorno a Ecuador desde España: Estrategias económicas, sociofamiliares y afectivas para una reintegración transnacional, realizado entre 2012 y 2013 por Gioconda Herrera, Cristina Vega, María Isabel Moncayo, Grégory Dallemagne y Lucía Pérez y financiado por FLACSO Ecuador. En total se realizaron 47 entrevistas en profundidad, 33 en Ecuador y 14 en España. Se analizan dos experiencias, la de los retornados de la comuna de Llano Grande al norte de Quito, una localidad de sectores populares con una larga historia migratoria, y la de los emprendedores, dispersos por la ciudad, que recibieron la ayuda del gobierno. 
la toma de decisiones?, ¿qué estrategias económicas, laborales, sociofamiliares y afectivas ponen en marcha? y, en términos generales, ¿cómo valoran la experiencia en su conjunto? Tal y como veremos, estos retornados muestran, con diferencias de género, una actitud ambivalente e incierta respecto a su presente y su futuro. La frase "Algo nos ganaremos aquí, veamos si algo sacamos", pronunciada por uno de los entrevistados, resumiría la actitud modesta y expectante que, en términos generales, caracteriza a un colectivo que, durante un tiempo, ha centrado el interés de la política pública de retorno.

El texto está organizado del siguiente modo. En primer lugar, abordaré de forma crítica la visión que desde la literatura se ha ofrecido sobre los migrantes como agentes de desarrollo económico a través del emprendimiento. En segundo lugar, señalaré la importancia teórica de analizar las estrategias de los retornados teniendo en cuenta la complejidad y la multidimensionalidad de sus iniciativas y formas de organizar el retorno. Para ello considero necesario adoptar una perspectiva que incorpore tanto las dimensiones socioeconómicas como las familiares y afectivas desde un enfoque transnacional de género y generación. En tercer lugar, se expondrá la metodología de la investigación. A continuación, se abordará el contexto de crisis en el que se produce el retorno, así como el cambio en la realidad socioeconómica y las percepciones subjetivas sobre la misma en Ecuador. En quinto lugar, se presenta el análisis de las motivaciones y estrategias del grupo de retornados protagonistas de este estudio, prestando especial atención al papel que desempeña el emprendimiento junto a otros elementos como la reagrupación de la familia, la posibilidad de volver al país con las hijas y los hijos, las opciones formativas de estos o la percepción de nuevas oportunidades en Ecuador. Veremos cómo el entretejimiento complejo de todos estos aspectos aparece junto a, o incluso por encima de, la apuesta por el negocio a la hora de dar cuenta del retorno.

\section{Enfoques críticos sobre desarrollo, emprendimiento $\mathrm{y}$ «retorno productivo»}

El estudio de las migraciones ha estado fuertemente atravesado por una visión de los migrantes como agentes eminentemente económicos y del comportamiento económico como tendente a la maximización del ingreso y la reducción de los riesgos que entraña la movilidad. Esta idea ha sido común en la perspectiva económica neoclásica, pero también en la nueva economía de la migración laboral (Arango, 2003; Lacomba, 2004; Parella, 2013). Esto ha llevado a pensar a los retornados como individuos y familias que se van porque las circunstancias económicas han dejado de ser favorables o que, una vez cumplidos sus planes, regresan en las mejores circunstancias. El retorno, en esta aproximación coste-beneficio, es una iniciativa necesariamente planificada que depende de la estimación de los recursos acumulados y de las ayudas a las que los migrantes hayan podido optar (Sjaastad, 1962; Todaro, 1969; Harris y Todaro, 1970; Stark y Bloom, 1985). En esta perspectiva, en 
la que subyace una concepción modernizadora del desarrollo, la migración y el retorno pueden evaluarse en función del «éxito» o del «fracaso» de las iniciativas planteadas ${ }^{2}$.

En paralelo a la crítica del carácter individualista, economicista y desarrollista que ha dominado estas aproximaciones, en las últimas décadas, se ha producido una importante reflexión sobre la contribución de los migrantes respecto al progreso de sus países de origen. Así, el crecimiento individual aparece en estrecho vínculo con el que tiene lugar en múltiples niveles: familiar, local, regional, comunitario y nacional. En efecto, el vínculo entre la migración y sus distintos retornos y el desarrollo se ha consolidado en la literatura (Fischer et al., 1997; Olesen, 2002; Kunz, 2006).

El acercamiento a esta relación ha oscilado entre contemplar a la primera como un motivo de pérdida de capacidad económica, dependencia y desestructuración social y familiar en el país emisor, más acorde con la visión estructuralista macro, o, por el contrario, como un elemento de dinamismo y aporte a través de flujos desiguales de recursos, remesas, activos, capacidades y afectos, una visión de corte micro más ajustada a la teoría de las redes sociales y la perspectiva transnacional (Portes y Walton, 1981; Sassen, 1988, Massey et al., 1987, Lacomba, 2004; Kunz, 2006; Cassarino, 2004; Abad, 2006; Cortés, 2010). Sin embargo, más allá de la polarización, históricamente secuenciada (Abad, 2006), entre dependencia y fuga de manos y cerebros o circulación productiva de recursos tecnológicos, financieros, laborales y culturales, cabría sostener una multiplicidad de vínculos situados entre los migrantes y el desarrollo de sus lugares de origen (Lacomba, 2004; Abad, 2006).

Dos han sido los principales ámbitos interconectados en los que se ha analizado esta relación: las remesas y los emprendimientos. Si bien las remesas han ocupado un lugar preponderante dada su magnitud en las últimas décadas, los emprendimientos, vinculados también a los procesos de retorno en el contexto de crisis de las economías del norte, están siendo objeto de atención. A esto se suma hoy el examen del impacto del capital y del talento humano, las «remesas sociales» y las cualificaciones formales, especialmente en países como Ecuador, donde el cambio de la matriz productiva se articula con la denominada economía social del conocimiento (Guarnizo, 1996; Coloma, 2011; Herrera, 2006; Vega et al., 2016a).

La contribución de las remesas descansa en los recursos monetarios que aportan y sus impactos a nivel macro (estabilización de la balanza de pagos, fuente de financiación y reducción de la pobreza) y micro (mayor disponibilidad de recursos monetarios en los hogares y en las comunidades, así como destino de los mismos para la salud y la educación). Esta suerte de «democracia financiera incluyente» situaría el autoempleo en pequeños negocios como la columna vertebral de un nuevo modelo de desarrollo local (Pérez Orozco,

2. El funcionalismo, que caracterizó a la visión de la migración como elemento modernizador, se perpetúa en la proyección del retorno productivo, al entender la migración como una experiencia de desarrollo exportable a los países de origen (Guarnizo, 1996; Cortés, 2011). 
2007 Roncken y de la Torre, 2009), que ha encontrado un lugar en la política pública de algunos países de América Latina, si bien, a día de hoy, apenas aparece conectada a la economía social y solidaria (Coraggio, 2012; Canales, 2006; Bakker, 2006). De este modo, los ahorros obtenidos en la migración se canalizarían de forma adecuada a través de inversiones productivas, lo cual generaría medios de vida locales autosostenibles durante el tiempo vivido en el extranjero, pero sobretodo después del regreso. En su revisión de la literatura sobre retorno y emprendimiento, Victoria y Paredes (2013) señalan el énfasis que los estudios otorgan a las condiciones favorables para un retorno "productivo" de los migrantes, si bien advierten que, además, han de darse ciertas condiciones que apuntan a la responsabilidad de los estados: un entorno económico fuerte y estable, una iniciativa institucional consistente, fácil acceso a financiación, habilitación de infraestructuras, así como un contingente de migrantes dispuestos a invertir sus distintos capitales (financiero, humano, social, migratorio). Cortés (2010) llama la atención sobre el uso político de un discurso gubernamental vinculado a la cooperación para el desarrollo y, en algunos casos, a la academia, desde el que se enfatiza el «mal uso de las remesas» en un marco de capacidades individuales. Este se presenta como contrario al desarrollo al revertir en más migración. La impronta política de esta concepción se expresa en las iniciativas de cooperación al desarrollo justamente en una coyuntura en la que el esfuerzo de los estados receptores se dirige a desactivar la presión migratoria.

La convergencia de las condiciones institucionales, económicas y humanas no siempre se da, pero además resulta cuanto menos problemático asumir que todos los migrantes han logrado ahorrar, han podido invertir adecuadamente, han aumentado su capital humano o han trenzado redes (trans)nacionales de cara un potencial emprendimiento. Muchos migrantes comienzan un negocio, tanto en destino como en origen, al no encontrar una salida laboral que responda a las expectativas ni a las cualificaciones desplegadas antes y durante la migración. Emprenden, por lo tanto, como una estrategia de subsistencia, por «necesidad» y no por «oportunidad» (Newland y Tanaka, 2010). Esto hace que sus negocios respondan más a un modelo de autoempleo cuentapropista en talleres domésticos que a pequeñas empresas con trabajadores y expectativas de crecimiento ${ }^{3}$.

Además de esta confluencia virtuosa de condiciones, la correlación entre retorno, emprendimiento y desarrollo suscita otras dos reflexiones críticas. La primera tiene que ver con el peso otorgado al emprendimiento en el retorno respecto a otros aspectos de la vida social simultáneamente valora-

3. Es importante advertir, en este sentido, la relación entre migración, emprendimiento y estructura de los mercados laborales, tanto en origen como en destino, así como en las dinámicas transnacionales que conectan estas localizaciones. Tal y como señalan Arjona y Checa (2007) para el caso español, las condiciones de flexibilidad, irregularidad y salarios bajos contribuyen a que los migrantes inicien negocios en periodos de crecimiento, aprovechando la capacidad adquisitiva de sus compatriotas ocupados y como una forma de escapar a las condiciones precarias de los mercados secundarios. 
dos a la hora de regresar y asentarse. La segunda se refiere a la concepción del desarrollo que subyace al fomento del emprendimiento como estrategia para el retorno.

Con respecto a lo primero, los estudios han puesto de manifiesto que las motivaciones para regresar no son únicamente económicas. Martínez (2015), en un reciente análisis del retorno de migrantes bolivianos desde España, sostiene que, a pesar de que muchos varones expresan su anhelo de volver para tener su propia empresa, esta motivación se asocia a la vulnerabilidad social y familiar, al estudio o al cuidado.

Por otro lado, la decisión de regresar no siempre coincide con el proyecto que se ha venido gestando, en ocasiones dirigido a permanecer en destino (Sanz, 2009). Muchos migrantes deciden finalmente volver por distintas circunstancias, de forma notable por la precariedad a la que se enfrentan. Si sus ahorros no se han desplegado en origen, estos retornados sobrevenidos se encontrarán con peores condiciones.

En relación con lo segundo, desde el paradigma del desarrollo humano, se cuestiona el modo en que se piensa la contribución de remesas y negocios al desarrollo bajo una concepción cuyo epicentro es el mercado. Esto perpetúa una visión individualista, localista y economicista del desarrollo según la cual este se transfiere a sujetos individuales y, de forma secundaria, a sus familias y comunidades, desatendiendo el papel de los cambios estructurales y la responsabilidad de las instituciones ${ }^{4}$. Si bien las remesas contribuyen a cubrir necesidades básicas de las familias, generando en algunos casos nuevos desequilibrios locales, su impacto macro en la reducción de la pobreza se ha demostrado limitado, además de arrojar dudas sobre su sostenibilidad en el tiempo (Acosta, 2006). Desde la economía feminista, se evidencia que el énfasis en las remesas y/o junto al emprendimiento proyecta una concepción del varón en tanto proveedor que no siempre responde a la realidad (Pérez Orozco, 2007) 5 .

El discurso sobre el retorno productivo perpetúa una concepción de la práctica económica, que, como ya señalara Schumpeter, eleva al emprendedor autosustentado a una estatura heroica y solitaria. Además de una construcción ideológica, se trata de un mecanismo de subjetivación propio de la etapa neoliberal (Rowan, 2010). Sobre la espalda de los migrantes descansa la tarea de impulsar el desarrollo de sus comunidades y el crecimiento económico (y no simplemente el sostenimiento basado en consumos y en usos improductivos).

4. Otra crítica, en este caso desde el postdesarrollo, se dirige a las concepciones de la modernidad eurocentradas para imaginar un desarrollo alternativo desde abajo (Escobar, 1996 y 2005). Al abrigo de esta última se daría primacía al emprendedor social frente al comercial, siendo la diferencia entre ambos una cuestión de modificación profunda e innovadora de la actividad humana y la creación de valor en la redistribución y la reciprocidad más allá del mercado.

5. La idea de conflicto cooperativo, revisada por la economía feminista, permite dar cuenta de los acuerdos, las negociaciones y las confrontaciones que se dan al interior de las familias o de los grupos domésticos (Beneria, 2008; Agarwal, 1997). 
Sus ahorros se ven así sometidos a exigencias superiores a las que se espera de cualquier otro fondo salarial (Canales, 2006; García Zamora, 2003; Arroyo, 2004), lo cual contribuye a desplazar a las responsabilidades institucionales y a las solidaridades públicas en la generación de bienestar.

En el caso específico de Ecuador, esta imagen de los migrantes como agentes de desarrollo se fue gestando en varias fases. Tal y como explica Eguiguren (2011), si a comienzos de 2000 la construcción del sujeto migrante respondía a una virtuosa combinación de pobreza y criminalidad con su propio aporte a la descomposición del orden social. Esta visión cedería paso a otra en la que este aparecería más vinculado con la familia en tanto ámbito que asegura la reproducción social y con las remesas, representación emblemática del desarrollo. En ambos casos, la acción tutelar del Estado, y la frecuente caracterización de los migrantes como incapacitados pero productivos, apuntaría a esquemas alternativos. Actualmente, estos están siendo progresivamente sustituidos por otros en los que, si bien el migrante no es un sujeto necesariamente "exitoso", especialmente a causa de la virulencia del neoliberalismo que hoy asola Europa, sí cuenta con un potencial estratégico para reconstruir la "patria robada", que ha de ser convenientemente canalizado desde el Estado a través de una serie de políticas dirigidas a incentivar el retorno productivo.

Moncayo (2011a, 2011b) examina dichas políticas, específicamente las que se dirigen a potenciar a los migrantes como emprendedores, y concluye que proyectan una visión sesgada de los retornados. Así mismo, muestra que el alcance real de las medidas que fomentan el emprendimiento es limitado. Estas críticas conectan con lo ya señalado por Cortés (2009) siguiendo a Gupta, en referencia a cómo la agencia del progreso se transfiere desde el Estado hacia el individuo emprendedor en un ejercicio gubernamental que excede los estrechos márgenes del territorio nacional. A la captación de fondos a través de las remesas, le sigue una política activa de retorno especialmente dirigida a los ahorradores. De la renovación de la lealtad política transnacional de los ecuatorianos en el exterior (Cortés, 2011; Levitt y Glick Schiller, 2004; Ramírez y Ramírez, 2004) habríamos pasado a su recuperación, al menos de algunos, a través de iniciativas retóricas y políticas de retorno. Tal y como ha advertido Gil (2013), esta reorientación lleva aparejada una vuelta al orden «natural» de la nación (de origen) en tanto lugar propio y normal para los sujetos. El exilio económico responde, en todo caso, a un mundo económicamente ilógico.

En el presente artículo, y a partir de los hallazgos del trabajo de campo, se argumenta que el emprendedor añorado es una figura mítica que apenas responde a las experiencias de los retornados más emblemáticos. El carácter mítico de esta figura plantea una continuidad, tanto para los estados de destino como ahora para los de origen, en torno al migrante como encarnación de lo productivo. Por ende, dicho mito, en esta fase de política migratoria, contribuye a reavivar, en el contexto de la crisis europea, un imaginario dignificado sobre los migrantes en la medida en que recuperan la nación y contribuyen a desarrollarla en los confines del territorio nacional. 


\section{Aproximarse al retorno desde un enfoque transnacional de clase, género y generación}

Sumándonos a lo ya señalado en algunos trabajos sobre retorno, se entiende este no como el cierre definitivo de la migración mediante el que restituir el orden originario de la nación, sino como un desplazamiento que no es una simple vuelta a la situación inicial (Guarnizo, 1996; Cassarino, 2004; Durand, 2004; Cavalcanti y Boggio, 2004; Cavalcanti y Parella, 2013). Tanto la migración como el retorno no son un proceso lineal, sino que se desenvuelven en fases. Más que una «lógica» unitaria, racional y consistente, el retorno puede ser tentativo, exploratorio, de ida y vuelta e incluso reversible, haciéndose acompañar en muchos casos de desplazamientos ulteriores.

La pregunta por el retorno permanece latente a lo largo de la migración y puede reactivarse por distintos acontecimientos. Pocos migrantes se sustraen a esta condición y a la consiguiente e ininterrumpida reevaluación del proyecto en su conjunto (Sayad, 2000). El retorno no es un estadio o un estado, sino un tránsito material y subjetivo más o menos prolongado que puede desencadenar un planteamiento más consecuente: «el retorno de verdad», como dicen algunos. Cuando hablamos de retorno aludimos a este tránsito y al proceso de asentamiento.

Más allá de los factores económicos y específicamente laborales, las razones se entrelazan en configuraciones complejas en las que intervienen diversos factores:

1. La situación económica en origen y destino.

2. La situación sociolaboral de los miembros de la familia, incluyendo el empleo formal y otras contribuciones.

3. Las perspectivas de educación de los hijos y la formación de jóvenes y adultos.

4. Las redes familiares, de amistad y otras conexiones sociales en origen y destino.

5. Los sentidos de pertenencia y sus expresiones nacionales, transnacionales y postnacionales.

6. El estatus migratorio y de ciudadanía (residencia, nacionalidad, etc.).

7. Los recursos y las inversiones a ambos lados.

8. Las ayudas y las titularidades sobre derechos disponibles en uno u otro país.

9. Las historias amorosas, sexuales y de pareja.

10. La organización de la reproducción, la vida doméstica y los cuidados.

Todos estos aspectos son relevantes en la definición de las motivaciones y estrategias en el retorno.

Desde un enfoque transnacional de género, se analizan las diferencias en los motivos y en las estrategias desarrolladas por mujeres y hombres. Dilucidar entre qué adquiere más peso a la hora de tomar decisiones y qué puede cambiar el rumbo de las mismas dependerá no solo de las posibilidades y las concepciones acerca de qué será lo mejor para la familia en términos económicos, sino 
también de la concreción de los deseos y las oportunidades de sus distintos miembros (Stark, 1984; Grasmuck y Pessar, 1991).

Desplazar la figura del trabajador migrante varón ha hecho visible el papel de otros actores, como mujeres y niños, así como sobre otras dimensiones de la experiencia migrante entretejidas con el trabajo asalariado (Oso y Ribas-Mateos, 2013). Además, esto se ha visto acentuado por la feminización de las migraciones y su examen desde la década de 1980 (Morokvasic, 1984; Phizacklea, 1983; Anthias y Yuval Davis, 1992; Kofman, 1999; Oso y Catarino, 2009). La atención a lo que sucedía en los hogares y entre distintos hogares transnacionalmente interconectados ha sido importante para visualizar las diferentes experiencias. La literatura ha puesto de relieve el peso de las distintas dimensiones — laborales, reproductivas, financieras, sexuales, formativas, de derechos, etc.- a las que aludíamos, así como su articulación compleja: la estratificación ocupacional étnica, por género y lugar de procedencia (Fernández, 1983; Morokvasic, 1984; Hondagneu-Sotelo, 1999; Hochschild, 2000; Sassen, 2003; Anderson, 2006; Agustín, 2007; Benería, 2008; Parella y Oso, 2012); las formas de reproducción en familias transnacionales (Parreñas, 2005; Levitt y Sorensen, 2004; Herrera y Carrillo, 2009; Herrera, 2013); la utilización de los recursos financieros (Oso, 2007, 2009; Herrera, 2006); los vínculos que mujeres y hombres mantienen en destino (Goldring, 2001; Guarnizo, 1996); la conexión entre migración, amor y sexualidad (Kofman et al., 2000; Riaño, 2011), y la presencia generizada en los espacios públicos y asociativos (Vega, 1999; Gil, 2010).

Los estudios sobre el retorno también han revelado diferencias importantes en cuanto a las formas de plantear el regreso, lo cual ha mostrado, una vez más, que los hogares no son unidades ajenas a las relaciones de poder (De Haas y Fokkema, 2011). En su revisión de la literatura para el caso ecuatoriano, Herrera (2013) advierte cómo los estudios sobre retorno despegan en 2010, dirigiéndose fundamentalmente al análisis de las políticas en esta materia (Moncayo 2011a, 2011b), a las condiciones desencadenadas por la crisis en Europa, particularmente en España (Peris-Mecheta et al., 2011; Duque y Genta Rossi, 2009; Boccagni y Lagomarsino, 2011, Herrera, 2013), y, en menor medida, al papel que desempeñan las redes y los vínculos transnacionales (Sanz, 2009; Schramm, 2011, a la relación de este con el desarrollo (Cortés, 2011) y a las experiencias de reinserción al regreso (Hernández et al., 2010). Tal y como señala Herrera, son pocas las aproximaciones de género, tanto en lo que se refiere a las motivaciones como a las estrategias desplegadas en la nueva situación.

Sabemos que en algunos contextos las mujeres se han mostrado más reacias al retorno que los varones. Para ellos, la llegada conlleva prestigio, al menos en un primer momento, mientras que para ellas significa acarrear una pérdida de poder y una vuelta a los roles tradicionales. Las motivaciones femeninas aparecen más claramente relacionadas con el hecho de recuperar el vínculo con los hijos y con las responsabilidades de cuidado. Así lo demuestra el estudio de Martínez (2015), según el cual los varones bolivianos se proyectan en sus expectativas económicas y su rol como proveedores con negocio a su regreso, 
mientras que en las mujeres el peso recae en la proyección de hijos e hijas y en su cuidado. Así, el examen de las dudas que suscita el regreso en las mujeres aporta a una extensa discusión sobre la redefinición de las identidades y las relaciones de género en la migración, en este caso, la ecuatoriana (Suárez Návaz, 2004; Herrera, 2006; Pedone, 2006; Parella, 2005; Oso, 2011).

\section{El retorno a Ecuador. Crisis y oportunidades}

La denominada "estampida migratoria», causada por la crisis social, económica y política que vivió Ecuador a partir de 1999, llevó a muchos ecuatorianos y ecuatorianas a abandonar el país (Ramírez y Ramírez, 2004). De acuerdo con el Colectivo IOÉ (Gómez, Tornos y Colectivo Ioé, 2007), en tan solo cuatro años las estadísticas oficiales de empadronamientos en España pasaron de contabilizar 4.000 ecuatorianos (1997) a 400.000 (2002). A finales de 2004, la cantidad alcanzaba los 500.000.

Si bien España había sido un destino de intenso crecimiento de población ecuatoriana en la Unión Europea por más de una década, a partir de 2008, la llegada de migrantes descendió. Según datos del Perfil Migratorio del Ecuador (Herrera et al., 2012), no se trata tanto de una explosión del retorno en esta primera fase de la crisis como de una desaceleración de flujos. De acuerdo con el INE, en 2010, había 484.623 personas de origen ecuatoriano en España, pero esta cantidad bajaría a 308.174 en 2012. Los datos del padrón respaldan el descenso, si bien este también responde a las personas que adquirieron la nacionalidad española.

Según Herrera, los datos sobre el retorno ponen de manifiesto un primer crecimiento tímido de este (Herrera et al., 2013), que más tarde, como sucede con otros migrantes de la región andina, irá en aumento a partir de 2011 (Parella y Oso, 2012; Parella et al., 2014). Si, en 2008, volvían a Ecuador 10.999 ecuatorianos de origen; en 2012, esta cantidad ascendía a 23.638 . Parece clara, por tanto, la tendencia hacia un mayor retorno ${ }^{7}$.

En definitiva, el balance migratorio ha cambiado de signo, y los pronósticos avecinan que el retorno y la reemigración, particularmente entre los latinoamericanos, así como la salida de los propios españoles, irá en aumento, según el

6. Según los datos de la Estadística de Variaciones Residenciales (EVR) elaborada por el INE a partir de las altas y bajas en los padrones municipales, Parella y Petroff (2014) constatan que, entre 2007 y 2012, se registran salidas entre los cuatro colectivos de extranjeros más numerosos en España. Las bajas de rumanos pasan de 7.959 en 2007 a 33.227 en 2010; las de los marroquíes, de 30.912 en 2007 a 36.621 en 2010 y a más de 30.000 hasta el año 2012. Las bajas de ecuatorianos pasan de 17.977 en 2008 a 14.167 en 2009 , para luego alcanzar más de 20.000 en 2012. Finalmente, los bolivianos registran 12.172 bajas en 2007 y 15.539 en 2012.

7. Aysa-Lastra y Cachón (2013), citando datos del Ministerio de Educación, Cultura y Deporte de 2013, proporcionan un dato revelador: el descenso en la matrícula de alumnado extranjero, que, en el curso 2012-2013, es de 755.156, es decir, 26.080 alumnos menos que en el curso anterior, un 3,3\% en un solo año. Ese porcentaje supera el 15\% en el caso de Argentina, Uruguay y Ecuador (12.744 estudiantes menos que en el curso anterior). 
INE, al menos hasta 2020, aunque es aventurado hacer un pronóstico (Arango et al., 2014).

El impacto de la crisis sobre los migrantes se ha dejado sentir en distintos aspectos. Aquí podemos llamar la atención sobre dos particularmente llamativos en el retorno a Ecuador desde España: el desempleo y el empleo temporal precarizado y la situación de la vivienda. Otras vertientes de la crisis, como los recortes en educación y sanidad o la agudización del clima de desafección política e institucional, tendrían, así mismo, que ser consideradas en relación con el retorno y la reemigración. La expectativa de obtener la nacionalidad española por parte de un colectivo que, frente a otros de migración más reciente, lleva más tiempo en el país, también han desempeñado un papel importante (666.000 entre 2002-2011, Aysa-Lastra y Cachón, 2013). Los marcos normativos (visado, regularización, reagrupación, nacionalidad, etc.) se convierten en un elemento estructural crucial en la dinámica del retorno. Junto a esto, los cambios y las percepciones de la coyuntura en Ecuador resultan igualmente claves para sopesar los desplazamientos. Además de tener un impacto palpable en las condiciones de vida, la crisis ha ido conformando en los últimos años un clima que ha penetrado la vida cotidiana de la población (Navarro et al., 2011).

Según datos del INE, la tasa de desempleo al finalizar 2013 era del 25,93\% para los españoles. En referencia a esa misma fecha, la SENAMI, citando un informe de la Defensoría del Pueblo de Ecuador, proporcionaba una tasa para los ecuatorianos que ascendía al $67,8 \%$, un dato posiblemente abultado si pensamos que para el conjunto de la población extranjera se eleva aproximadamente en más de doce puntos porcentuales.

En todo caso, la tendencia en relación con el desempleo del colectivo ecuatoriano en España ha sufrido aumentos constantes, puesto que pasó de 38.675 en el año 2005 a 68.803 en 2008, y se disparó a 162.957 en 2009. Por lo que respecta al sexo, se puede observar que, entre 2005 y 2007, las cifras de desempleo entre las mujeres fueron mucho más altas (30.018) que entre los hombres (13.880), hecho que cambió en 2008, cuando la cifra de hombres desempleados (36.780) sobrepasó a la de mujeres (32.023), dado el impacto de la crisis en la construcción frente a otras ramas como el cuidado (Gómez et al., 2007; Martínez, 2011). Como veremos, esta circunstancia podría representar un acicate para el impulso masculino hacia el retorno, pero, sobretodo, para la preeminencia de las motivaciones vinculadas al trabajo.

Del mismo modo, y recogiendo los datos del informe de Gómez et al. (2007), el empleo de baja calidad aumentó. Las cifras subieron un 4\% para los autóctonos y un 56\% para los inmigrantes (el 55\% para los latinoamericanos) entre 2007 y 2011. Se incrementó, así mismo, la rotación entre ocupación y desempleo. El empleo temporal descendió en 2010 y volvió a subir en 2011, especialmente para las mujeres inmigrantes. Entre 2008 y 2011, se produjo una caída generalizada de la ocupación de asalariados temporales en todos los grupos nacionales. Las mayores pérdidas correspondieron a los trabajadores de Ecuador y Bolivia (un -42\%), seguidos de los de Argentina (un -36\%), Marruecos, Rumanía y Colombia (más del 20\%). 
Entre 2006 y 2010, el salario medio descendió en mayor medida para los migrantes (un $-10,6 \%$ ), de forma significativa, entre los varones (un -14\%). El aumento de los parados inmigrantes sin experiencia laboral también es un dato relevante, por lo que, en el aludido informe, se habla de «embalsamamiento de jóvenes inmigrados» (2007: 9), lo cual redundaría en un mayor impulso hacia el desplazamiento. Según los datos recogidos por Parella y Petroff (2014) para 2012, el 55\% de las salidas se producen dentro del grupo de edad laboral (25-44 años). No deja de llamar la atención que, según la EPA (2012), el 12\% de los retornos corresponda a jóvenes con edades comprendidas entre los 16 y los 24 años, una franja de edad que presenta las tasas más altas de desempleo, tanto en el caso de la población extranjera como de la española (un 55\%). También resultan significativas las bajas en edades comprendidas entre los 0 y los 15 años, un 11\% del total, lo cual hace pensar que las salidas están siendo familiares.

La crisis ha acentuado el empobrecimiento de los hogares migrantes ${ }^{8}$, cuyo nivel de protección por parte del sistema de seguridad social se ha visto reducido. La contracción del gasto también es reseñable. En 2010, el gasto medio por persona en los hogares españoles suponía el 104\% de la cifra media total en España, mientras que el de los inmigrantes apenas alcanzaba el 64\%. Esto está relacionado con las dificultades para afrontar gastos y deudas, particularmente en el caso de la vivienda. La tasa de pobreza en los hogares inmigrantes (un 31\%) supera en 12 puntos a la de la población autóctona menor de 65 años (un 19\%).

Con respecto a la situación de la vivienda, son conocidas las dificultades para afrontar el endeudamiento. De acuerdo con el informe anteriormente citado de la Defensoría del Pueblo en Ecuador, en 2007, al menos el 27\% de los ecuatorianos tenía una hipoteca a su nombre. Se trata del colectivo de extranjeros con vivienda hipotecada más numeroso (menos del $9 \%$ vivía en una casa ya pagada $)^{9}$. Según una estimación, entre 8.000 y 15.000 familias ecuatorianas se enfrentaron a una ejecución hipotecaria. En abril de 2009, el Banco de España afirmaba que la tasa de morosidad hipotecaria de los inmigrantes era del $12,5 \%$, mientras que la del resto de la población solo alcanzaba el 1,6\% (Colectivo IOÉ, 2013)

El tradicional discurso hegemónico en España sobre la vivienda en propiedad se conjugó con el boom inmobiliario y crediticio para desencadenar

8. Según estimaciones del Colectivo IOÉ (2013), la tasa de pobreza de los hogares de personas inmigrantes es del $31 \%$, superando en 12 puntos la de la población autóctona menor de 65 años (19\%). También ha aumentado la pobreza extrema (10,8\% y 6,7\%, respectivamente).

9. El $50 \%$ de los propietarios ecuatorianos hipotecados destina el $75 \%$ de sus ingresos al pago de la misma, cuyos tipos de interés registraron un incremento exorbitante entre $2007 \mathrm{y}$ 2008. Más del 56\% de los ecuatorianos y de las ecuatorianas pagaban importes superiores a 700 euros en concepto de cuota mensual de la hipoteca o del alquiler (Defensoría del Pueblo de Ecuador).

10. Según datos de la Plataforma de Afectados por la Hipoteca (Colau y Alemany, 2012), la mayor parte de las hipotecas se firmaron en 2006 o antes, el $89 \%$ de los desahuciados intentó renegociar con el banco y la mitad está en paro. El 65\% son españoles y el 35\%, extranjeros. En 2012, se realizaron alrededor de 180.000 desahucios. 
este fenómeno, que encontró su contraparte en el deseo y la cultura de la propiedad vinculada al mercado financiero hipotecario en los países de origen de los migrantes, siendo el caso de los ecuatorianos una buena ilustración de este encaje (Suárez, 2014). Muchos de los que invirtieron en destino tuvieron que dejar su vivienda, lograran o no la dación en pago, con lo que perdieron su espacio vital, así como buena parte de los ahorros conseguidos. Tal y como señala Macarena Suárez (2014), en la medida en que la vivienda es el significado moral y económico de la persona, el desahucio constituye un despojo que destituye y margina socialmente.

Con respecto a la situación en Ecuador, se abren nuevas expectativas para el periodo del estudio. El economista Alberto Acosta (2013: 12) señala cuatro elementos clave que han permitido el crecimiento de la economía ecuatoriana: el petróleo, que, además, elevó su precio entre 2007 y 2011; los tributos; los préstamos del Instituto Ecuatoriano de Seguridad Social (IESS), y la renegociación de la deuda externa. Esto ha repercutido en el incremento de la inversión pública, que pasó de 7.891 millones de dólares en 2006 a 23.803 en 2011 y que se dirigió en buena medida al gasto social, particularmente en educación y salud. También se ha reducido la pobreza gracias a ayudas financieras focalizadas del gobierno, aunque la brecha de desigualdad se mantiene ${ }^{11}$. Entre las dificultades, Acosta apunta al bajo desarrollo de la producción nacional y el sector agrario, donde la concentración de tierras no ha permitido una reforma en profundidad. Ambas cuestiones condicionan la situación del empleo ${ }^{12}$. El subempleo y el empleo informal en la zona urbana es muy llamativo (un $44,7 \%$ en 2013) y la política dirigida a la inserción laboral sigue siendo una asignatura pendiente. Las reformas laborales apuntan a una ordenación del trabajo dirigida a la flexibilidad y a la competitividad en el marco del cambio de la matriz productiva.

Así pues, en este periodo denominado "postneoliberal», destaca una decidida dinámica de reformas de carácter protector, junto a un impulso hacia la reinserción competitiva de Ecuador en el mercado global, aún anclada en la economía extractiva y en el sector primario exportado. Hay que llamar la atención sobre aquellas iniciativas específicamente dirigidas a los migrantes y los retornados, que, como indicábamos arriba, han buscado restituir su dignidad en el discurso nacional. En estas políticas, se ubica el programa «Menaje de casa», las ayudas y los incentivos fiscales al emprendimiento, el bono para la compra de vivienda, los programas de atención especial para hijos de retornados, las líneas de crédito preferencial y, más recientemen-

11. De acuerdo con el Centro de Derechos Económicos y Sociales (2013), el gasto social relativo no ha ido acompañado de una política fiscal progresiva que grave a los grupos económicos más fuertes, que hoy se encuentran en franca expansión. Las brechas del ingreso por estrato social se han reducido entre las clases medias y medias-altas, no así en los sectores más pobres. En 2012, sus ingresos aumentaron el 4,1\%, frente al 52,5\% de los más acaudalados.

12. Según datos de la última Encuesta Nacional de Empleo y Desempleo (ENEMDU) del Instituto Nacional de Estadística y Censos (INEC), el desempleo urbano representaba el $4,6 \%$ en marzo de 2013 , y el subempleo, el 44,7\%. 
te, los programas de inserción laboral para profesionales en el sector de la educación y la salud. El Fondo Cucayo dirigido al retorno productivo ha sido un programa estrella, si no por la cobertura (un $9 \%$ de los proyectos presentados), sí por su valor simbólico ${ }^{13}$.

Todo ello, unido a las repetidas alocuciones a los migrantes del presidente Rafael Correa, en un decidido ejercicio de "transnacionalismo político» (Ramírez, 2013), contribuyó en este periodo a generar un clima de expectativas que la población en el exterior percibió como una oportunidad para considerar el retorno como una opción no solo viable, sino también deseable.

\section{Metodología}

El presente artículo está basado en una investigación más amplia sobre retorno a Ecuador desde España. En ella se adoptaron tres puntos de partida metodológicos:

1. El enfoque transnacional con entrevistas multilocales.

2. La familia como unidad de análisis.

3. Una perspectiva de género y generación que permita entender las diferencias al interior de la misma.

Las limitaciones de la muestra se refieren a su extensión. No obstante, la metodología ayuda a captar los diferentes enfoques de los miembros de la familia, así como la dinámica transnacional multisituada en la que se dirime el retorno.

Se parte de la familia como unidad de análisis considerando las diferencias en su seno, así como de la concepción del retorno como proceso dinámico y escalonado. Se realizaron entrevistas a retornados, todos ellos perceptores del Fondo Cucayo en los dos ciclos del programa 2008-2010 y 2010-2012, en Ecuador y a sus familiares en España. Esta metodología multisituada permitió conocer el desarrollo del retorno desde el punto de vista de los actores según el género y la edad, y en relación con los modos en que unas y otros explican los motivos y las estrategias que rodean el camino de vuelta. Se acude a la técnica de entrevistas en profundidad semiestructuradas, privilegiando su desarrollo en el espacio de trabajo. Estas giran en torno al proyecto migratorio, a las motivaciones para quedarse o volver, a las estrategias individuales y de conjunto emprendidas para tal fin y a los conflictos asociados.

Los entrevistados, hombres, mujeres y jóvenes de ambos sexos, pertenecen a distintos tipos de unidades según tamaño, composición y lugar de residencia de sus miembros:

13. El aporte de la SENAMI era del $21 \%$ en 2013, y el de los perceptores, el $79 \%$. El total de la inversión compartida representaba 1.192 .700 dólares, un 29\% de los cuales correspondía al fondo gubernamental, y un $71 \%$ fue la contraparte de los migrantes. El promedio de inversión total por emprendimiento es de 40.000 dólares. El fondo funciona conjuntamente con otras iniciativas financieras. 
1. Familias retornadas con dos progenitores e hijos.

2. Familias con un progenitor (varón) o hijos en España.

3. Familias retornadas encabezadas por mujeres.

Dado que el contacto fue facilitado por la SENAMI, tratamos de recoger diversos negocios: mecánica, cerrajería y soldadura, costura, construcción, lacado de uñas, empresas de Internet, así como otros menos comunes, como una academia deportiva, una residencia de ancianos o una iniciativa de comercialización de software. Todos ellos responden a iniciativas familiares y, en su mayoría, se trata de talleres pequeños y medianos escasamente tecnologizados $\mathrm{y}$ sin apenas empleados.

El perfil de los entrevistados corresponde al de quienes migraron a raíz de la crisis de finales de la década de 1990. Se emplearon en los sectores más emblemáticos entre los migrantes latinoamericanos: servicio doméstico y cuidado y comercio para las mujeres, y construcción para los varones. Reunificaron a sus familiares, los que así lo hicieron, entre 2002 y 2004, y arreglaron permisos de residencia y nacionalidad con anterioridad al retorno, siendo esta una característica particular de la población ecuatoriana que la diferencia de otros colectivos que, como el boliviano, llegaron a España de forma más tardía y optaron por una estrategia de retorno más temprana. Responde, como decíamos, a sectores de clase media que lograron los ahorros que les permitieron abrir sus negocios y respaldar las ayudas.

El retorno, en todos los casos, se produjo entre 2008 y 2012, es decir, aparece directamente vinculado a la crisis. Todos ellos son, en este sentido, buenos exponentes del proceso de migración y retorno entre España y Ecuador. También lo son en lo que se refiere a la edad, puesto que la mayoría de los adultos se sitúa, en el momento de migrar, en una franja media de la edad laboral, entre el grupo más joven (menores de 34 años) y el intermedio (de 35 a 44 años) (Gómez et al., 2007). Si consideramos su nivel educativo y su último empleo, vemos que se trata de personas con un nivel de formación medio, si bien lo más característico en su perfil es el haber tenido un negocio anteriormente, aunque muchos trabajaran en España como empleados.

\section{Estrategias socioeconómicas, familiares y afectivas de los retornados. Mitos y realidades}

Tal y como argumentamos al inicio, las motivaciones y las estrategias en el retorno no pivotan en torno al emprendimiento, sino que este se entreteje con otras dinámicas individuales y familiares. En ellas es clave el límite objetivo pero también subjetivo que marca la crisis en España. Este se vincula con los ciclos de vida familiar, es decir, con los periodos cambiantes en la existencia migratoria, que se conforman como una compleja articulación de empleos, trabajos, formación, vida social y afectiva, y cuidados. Esta dinámica varía según el género y la edad. Las expectativas de futuro de la unidad familiar y sus distintos miembros se vinculan a los proyectos gestados en la migración, así 
como a los virajes que estos experimentan, en este caso, a causa de la coyuntura socioeconómica.

\section{1. "Tiempo de volver». Crisis y emprendimiento como motivaciones para el retorno}

El trabajo de campo realizado pone de manifiesto la diversidad de situaciones al interior de este colectivo, que como indicamos, representa al sector más «exitoso». Llama la atención, en este sentido, las diferencias que existen entre, de una parte, aquellas familias que en su proyecto optaron por una «lógica de retorno» o, en todo caso, por una lógica múltiple $y$, de otra, quienes apostaron por una "lógica de permanencia» aunque mantuvieran existencias transnacionales (Sanz, 2009; Martín, 2012) ${ }^{14}$. Entre los segundos, la crisis ha terminado haciendo primar el regreso, si bien esta orientación más tardía les ha desprotegido en relación con quienes realizaron inversiones económicas, sociales y formativas sostenidas a ambos lados. En este sentido, se puede afirmar que quienes «trabajaron» por quedarse y no pudieron hacerlo han encontrado mayores dificultades.

Conectado con lo anterior se advierten distintas formas de operar en las familias transnacionales. Encontramos a aquellas que movilizaron a sus integrantes en ambos países en lógicas extensas y múltiples y a otras que se «movieron» en bloque, focalizando sus recursos de forma prioritaria en uno u otro país. Las primeras pudieron poner en marcha retornos escalonados, enviando a algunos miembros a casa, en general a los más jóvenes con propósitos formativos, o realizando viajes exploratorios antes de dar el paso definitivo. Este es el caso de Emilio, que tras un primer retorno y una reemigración en que pudo tantear las oportunidades económicas en Ecuador, envió a su hermano de 18 años como avanzadilla y después regresó él para montar un negocio que diera cabida a otros miembros. En estos momentos, espera a sus padres y, quizás, a alguno de sus hermanos.

Mis hermanos están entre que sí, entre que no, entre que esto..., decidiéndose todavía, pero mis padres dijeron, o sea, ya, o sea, ya, que se vaya el Michael, que es mi hermano el menor. ¡Ya!, jya nos regresamos! Entonces, lo que están esperando mis padres es entregar el piso, que les coja el banco ya el piso y se queden sin deuda, porque el aval es mi hermana la mayor.

14. En la primera primarán el ahorro, el envío de remesas (mantenimiento de la familia e inversiones), el pluriempleo, el trabajo intensivo, la residencia en el trabajo (empleadas de hogar), la cohabitación en el hogar, el fuerte vínculo comunicativo con familia y allegados, las relaciones sociales con compatriotas, etc. En la segunda se va construyendo el arraigo, priorizando la residencia y la nacionalidad, la búsqueda de opciones laborales mejores y que permitan disfrutar de más tiempo libre para la conciliación, la reunificación y la residencia familiar, la compra de vivienda, la homologación de títulos, la formación, el espaciamiento de envíos y comunicaciones y la ampliación de redes, vínculos y formas de participación en destino. Ninguna se presenta en estado puro. 
En cambio, las familias monomarentales han encontrado mayores dificultades para regresar y son las que se muestran más ambivalentes respecto a su vuelta a Ecuador, tanto en términos socioeconómicos como afectivos. La feminización de la pobreza en la migración, pero también en el retorno, es un elemento clave para entender esta situación (Martín, 2012). De manera distinta, también para los varones que migraron solos con fines laborales y enviaron dinero a casa, el retorno ha sido difícil, tanto en lo económico como en lo afectivo, y ha dependido, como explicaré, de los vínculos económicos, familiares y afectivos cultivados durante la migración.

Otro elemento que diferencia los retornos y su asociación a emprendimientos tiene que ver con la situación de salida de España y su grado de planificación. Entre los retornados, encontramos a algunas unidades que pudieron anticipar la crisis y otras para las que el regreso se produjo después de un largo periodo de aguante en el que apuraron la posibilidad de permanencia. Quienes "olfatearon" la crisis pudieron vender sus viviendas o su negocio en mejores circunstancias. Este fue el caso de Luis, que liquidó su empresa de hostelería e invirtió en otra de limpieza en Quito.

[...] trabajamos 3 años y medio sin descansar un día. Ganamos muchísimo dinero, muchísimo dinero, y logramos vender en una muy buena cantidad de dinero, en euros, vendimos y todo ese dinero trajimos acá. Nos fue muy bien, vendimos eso y comenzamos. [...] Ya he hecho lo que he podido, lo que más he podido, y me regreso a mi país, nos regresamos, yo y mi esposa y mi hija la más pequeña, que está en Canadá. [...] antes de eso, optamos cada quien, mi esposa, yo, mi otra hija la pequeña, por la nacionalidad. Somos españoles, nacionales. Tenemos la doble nacionalidad, ecuatoriana y española. Entonces optamos por venir acá.

Generalmente, se trata de migrantes, estos sí, con un perfil emprendedor claro, que obtuvieron holgados beneficios como empleados, los invirtieron en negocios, incluso en bienes financieros, además de en vivienda, desmontando antes de la debacle. Cabe aquí distinguir entre aquellos para los que el negocio es una oportunidad, abierta en origen y conectada a la propia migración, y aquellos para los cuales el negocio representa más bien una alternativa de supervivencia frágil y tentativa. Para estos últimos, como explican De Haas y Fokkema (2011), el emprendimiento es el resultado del efecto "yo también», igualmente cargado del potencial mítico al que aludíamos.

En efecto, asociar emprendedores a retorno planificado y, por lo tanto, exitoso resulta aventurado cuando no irreal. La imagen secuencial del retornado como alguien que ya tiene un negocio y que, en el contexto de crisis, planea liquidarlo de la mejor manera posible para transferirlo gracias a una ayuda del gobierno no es generalizable. De hecho, muchos armaron un negocio careciendo de experiencia previa, pocos fueron los que lograron trasladarlo y muchos pidieron la ayuda cuando ya llevaban tiempo en Ecuador, bien por enterarse de su existencia, bien por una emergencia sobrevenida. 
Este último es el caso de Sania, que regresó con su hijo al perder su locutorio en España. A su regreso a Quito, abrió otro, pero fue víctima de un robo y entonces pidió la ayuda.

[...] a partir del robo es que yo me acerqué a la SENAMI. Yo tenía que tener una contraparte, y según la contraparte que yo tenía, y según el negocio que teníamos, nos daban la cantidad de dinero. Pero como lo mío era solamente esto de cabinas, pues me dieron 5.000 dólares. Con eso he comprado algunas cosas [...] La SENAMI nos ha dado dos años. Si yo me estoy aguantando aquí es por la SENAMI, pero la verdad es que los negocios van pésimo, pésimo. [...] Yo he tenido que rendir cuentas del dinero que me ha entrado. Bueno, como es un dinero del Estado, pues tienen razón. Y ahí estoy, esperando que las cosas mejoren.

Lo que sí parece claro en todos los casos es que la ayuda del gobierno fue una importante contribución, si bien nadie volvió por contar con ella. Su influencia como desencadenante del retorno es limitada, como limitado es el peso del negocio como motivación principal para el regreso. Armar un negocio es una opción, pero no el móvil. Este responde más bien a una articulación de elementos de distinto signo en el que las alternativas económicas se entretejen con otras de carácter familiar y afectivo: familia y recursos en origen, añoranza del Ecuador, expectativas formativas o laborales de los hijos, hartazgo y clima de la crisis, deseo de experimentar en la nueva coyuntura del país, además de proyectos económicos más o menos fraguados. El peso de su decisión varía enormemente según el género. Mientras los hombres, al igual que señala Martínez (2013) para el caso del retorno a Bolivia, enfatizan sus estrategias laborales, ya se basen en trabajos por cuenta propia o ajena, las segundas tienden a dar más valor a los vínculos y arraigos familiares. Los varones entrevistados se proyectan como proveedores ocupados en oficios más que como emprendedores. No olvidemos que, en la mayoría de los casos, se trata de pequeños negocios familiares que tienen más que ver con el taller de un trabajador autónomo que con una empresa. El caso de las mujeres, salvo excepciones, es un poco distinto, ya que el tipo de negocio que ellas abren por iniciativa propia (lacado de uñas, hospedaje o locutorio) no aparece tan asociado a su identidad previa como profesionales, sino que forma parte de estrategias de supervivencia vinculadas al mantenimiento del hogar.

La crisis constituye un límite abierto y subjetivo que muchos invocan tras una permanencia de más de una década en España. Así lo explica Alberto, que migró solo, trabajó en la construcción y, a su regreso, retomó un viejo negocio de soldadura en su domicilio.

La razón de mi regreso era que ya se puso un poco difícil ya en España también. Entonces dije: «Mi familia vale más», y me regresé, la verdad [...] Todos estos años trabajé para la misma empresa hasta cuando ya me despidieron ellos, porque justamente ya entró la crisis. Ahí al menos, en Castilla la Mancha, era el auge de la construcción, la que más construía a nivel de España. Entonces 
eso se terminó. Fue de un momento a otro que las empresas comenzaron a quebrar. Entonces el propietario me dijo que no había trabajo y cerró.

¿Usted se hubiera animado a quedarse si la cosa hubiera ido de otra manera?

Yo estaba un poquito cansado, la verdad, porque diez años de estar separado de la familia, ya muchas veces uno ya va tomando otras, otras ideas.

Sin restar importancia a los efectos materiales de la crisis en términos de renta o desposesión (vivienda, servicios, etc.), esta acaba proporcionando una plataforma propicia para dar un paso adelante en el que se dirime un amplio conjunto de cuestiones. En este sentido, la coyuntura económica contribuye marcando un límite que va más allá de sí misma: «tiempo de volver».

\subsection{Rearmar la familia, rearmar el negocio}

Tal y como explicábamos arriba, la familia es una unidad económica activa que articula a sus miembros de forma transnacional. Una estrategia propia para y en el retorno escalonado transnacional de las familias extensas, con un claro anclaje en el emprendimiento, tiene que ver con la progresiva reagrupación de todos sus miembros en torno al negocio. Esta estrategia implica al menos a dos generaciones, en algunos casos a tres. En estas unidades, hay un promotor, hombre o mujer, con un fuerte liderazgo, que va movilizando al conjunto de los integrantes a ambos lados en una única dirección. Según lo hallado en el trabajo de campo, cuando esta promotora es una mujer, el rearme del negocio en Ecuador, además de maximizar recursos financieros y laborales, tiene muy presentes otras dimensiones, como la formación de los hijos, la obtención de beneficios sociales o la consecución de la nacionalidad. La capacidad de integrar el vínculo entre negocio y familia es mucho más sólida cuando las mujeres están al frente de la empresa.

La estrategia consiste en dejar para lo último a aquellos miembros que aún puedan hacer aportes para la reproducción ampliada del grupo, ya sea a corto o medio plazo. Esta orientación, auténticamente planificada, incluye mantener en destino a aquellos miembros que aún tengan trabajo y cuyas rentas puedan aportar al negocio en destino, por ejemplo, a través del pago de deudas. También se quedarán aquellos cuya formación pueda, así mismo, reportar ventajas al regreso. Finalmente, se quedarán quienes estén pendientes de alcanzar beneficios sociales, como la jubilación, o administrativos, como la nacionalidad. Por el contrario, se primará el retorno de quienes puedan planificar el negocio familiar, trabajar en él o contribuir a la reproducción del hogar a través de los cuidados.

Muchos hogares migrantes se sostienen gracias a dos empleos. Cuando uno se pierde y el otro no alcanza, puede desencadenarse el retorno. La alternativa es la separación de la familia: unos se van y otros permanecen anclados en el trabajo o en la obtención de la jubilación, la nacionalidad o los estudios de los 
hijos. Más allá de que los empleos femeninos resistan mejor la crisis, en ocasiones no son suficientes para retener al conjunto de la familia. Así lo explica Ángela respecto a su hermana:

Ahora sí ya está pensando a venir [hermana], porque dice que está..., ya malo, y también los años nos pasan. «Ya no somos las jovencitas de antes», dice ella [...] ya es nacionalizada todo eso, tiene su doble nacionalidad, ¿no? Entonces, el marido, los hijos, porque ella llevó a todos, a todos los hijos. Ella tiene 4 hijos. Se compró el piso y quiere ya, le quitaron también porque no pudo pagar, se quedó sin nada, por eso [...] Ya está en proyectos de venir, porque prácticamente se quedó en la calle [...] Y ahora en esa familia, claro, las hijas ya se casaron, pero en esa familia solo está trabajando el papá, entonces él tiene que afrontar piso, comida y todo..., y para toditos. Claro, él está ahí, pero solo con el sueldo de él.

Cuando son las mujeres las que regresan primero preparan el terreno y reacomodan los desgastes afectivos provocados por migraciones prolongadas (Martínez, 2011). Según se advierte en las entrevistas, justamente este hecho les dota de un papel especialmente dinámico en el retorno productivo, al ser ellas el motor del rearme del proyecto conjunto de familia y negocio ${ }^{15}$. El caso de la señora Marianita es emblemático. Ella era costurera, pasó por el servicio doméstico, siguió cosiendo y llevó a su marido, a su hijo y a otros familiares. Decidió regresar para abrir una pequeña empresa textil junto a sus hijas en Ecuador. Ella planeó la estrategia: una hija inicia el taller solicitando la ayuda del gobierno, el hijo, que mantiene el trabajo en España, se va endeudando para comprar maquinaria al tiempo que se forma en su manejo, ella regresa y retoma el negocio juntando en torno suyo a hijos e hijas y cuñados y cuñadas dispersos tras su partida. Por último, el marido aguarda en España con el hijo para mirar por él y sostener el vínculo familiar que permitiría su eventual regreso al tiempo que espera la jubilación.

Si ya acabamos de pagar ese préstamo de mi hijo, él ya se siente más libre, ya puede endeudarse en otra cosa, porque lo que queremos es sacarnos una bordadora. Si mi hijo regresa, entonces mi hijo se encargaría de la bordadora, porque él tiene que estudiar, porque ya está viendo en Madrid los diseños de bordadoras para él aprender, porque si él viene acá, ya se endeudaría en la bordadora y él se pondría al frente de eso, porque tampoco va a venir acá a la desocupación, porque no estamos acostumbrados. Él no está para que diga "que mi mamita me mantenga», porque aquí saben coser todos mis hijos, hombres y mujeres, porque yo toda la vida he cosido.

Esta actuación estratégica revela el protagonismo femenino en las relaciones de género en la migración. El destino de los hijos e hijas en edad laboral,

15. Aun así, según datos de la SENAMI, el 70\% de los emprendimientos registrados obran a cargo de varones, hecho que pone de manifiesto el desequilibrio de género en la titularidad de los activos de la familia. 
tengan o no pareja en España, está abierto. Estos podrán incorporarse al plan familiar, sin embargo, su vuelta dependerá de factores —empleos, amores, formaciones - que pueden empujar en distintas direcciones. A pesar de las proyecciones de Marianita, su hijo, al igual que otros jóvenes en esta situación, manifiesta un cierto grado de autonomía respecto a los proyectos de quienes encabezan el regreso articulando la unidad familiar en torno a un negocio.

Existe una diferencia entre las que lideran el retorno y aquellas cuyo papel se centra en la atención a la familia y se hallan, más bien, en la trastienda del negocio realizando tareas de administración y comercialización (recepción o encargo de pedidos). En muchos casos, las mujeres, esposas e hijas son las que elaboran el plan y gestionan la solicitud del fondo, encargándose de los trámites necesarios. Estas tareas las compatibilizan con la atención al hogar y a sus miembros en la medida en que domicilio y negocio se ubican en el mismo espacio. Se reproduce, por tanto, una división sexual del trabajo al interior del pequeño emprendimiento familiar.

En todo caso, teniendo presente esta diferencia, uno de los hallazgos ha sido precisamente constatar el papel de liderazgo que tienen las mujeres en los negocios y el modo de entretejerlo con la familia. De la misma forma que hemos comprendido el papel de las mujeres a la hora de mantener unida a la familia transnacional, hoy entendemos que estas combinan de forma virtuosa familia y negocio en la articulación de una estrategia global de retorno que involucra a maridos, hermanos, hijos, e incluso nietos, a ambos lados. En general, cuando la estrategia de emprendimiento está regentada por hombres, estos suelen describirla no tanto como una forma de aunar a la familia dispersa, sino como un modo de autoafirmarse y/o dar un futuro a los hijos varones. «[... ¡ ¡yo tengo que volver a mi país, porque ahí al menos soy alguien!», decía una entrevistada aludiendo al sentimiento de inconformidad de su esposo.

\subsection{Retorno, educación de hija e hijos y ciclo de vida familiar}

El perfil sociodemográfico de los emigrantes ecuatorianos que llegaron a finales de la década de 1990 pone de manifiesto que estos se encontraban, y se encuentran, en edad laboral. Sus hijos nacidos en Ecuador llegaron después de dos o tres años de residencia. Hoy, estos padres y madres se ven impulsados a retornar porque saben que, de no hacerlo, es posible que su destino se separe geográficamente del de sus hijas e hijos menores de edad. Así lo expresa una madre que regresó con su hijo de 8 años, al que, según explica, «casi no me lo puedo traer».

[...] ya se decía que iba a haber una crisis y, ¡qué vamos a hacer los emigrantes! Pues que ya no iba a ir bien el negocio. Todas esas cosas nos hizo pensar en volvernos, aunque mi hijo no, no quería, casi no me lo puedo traer a mi hijo. Y también quería que mi hijo siga la universidad aquí, porque yo decía: «Si me quedo allá, pues ya me tocará quedarme unos 5 años de una vez para que él estudie, ¿¿no?». O bien me venía a que el comience aquí, o bien me queda- 
ba allá, definitivamente allá. Yo tenía que quedarme para no interrumpir los estudios del chico.

Así como muchos varones emprendedores proyectan el negocio que iniciaron al retorno sobre sus hijos, para las mujeres jefas de hogar con negocios de subsistencia su motivación principal para regresar es proporcionar una oportunidad educativa a sus hijos, algo difícil en el contexto español debido al encarecimiento de las matrículas y a las calificaciones que se precisan para elegir el grado. La gratuidad de las universidades públicas ecuatorianas es un elemento atrayente de cara al retorno, si bien pocos advierten que también resulta difícil la elección de los estudios (Vega et al., 2016b).

Los ciclos educativos, asociados a la edad, junto a la situación económica son claves para estimar el retorno. La minoría de edad facilita la opción de regresar. Tratan de amortiguar el impacto acudiendo a distintas estrategias emocionales, a pesar de lo cual muchos niños y niñas atraviesan un dramático proceso de desarraigo al comienzo. Así lo explica Leandra, cuya hija, Paulina, llegó a España con 2 años y regresó con 14: «Tú no le hables de volver [le decía a su esposo]. Simplemente vamos a ir y vamos a probar, vamos a ver si resulta y si no volvemos». Al final, fue una mascota lo que logró calmar su desconsuelo. Ahora Paulina tiene 18 años, tiene novio y solo piensa en volver a España de forma hipotética para estudiar una maestría.

La proyección formativa de los hijos aparece como una estrategia fundamental para las madres, quienes, tras su experiencia laboral en sectores devaluados en España, aspiran a ver a sus hijas e hijos como profesionales, escapando a los procesos de discriminación a los que se han visto sometidas (Pedreño, 2005). Como advierte Parella (2013), la movilidad social de estos jóvenes es limitada y muchos heredan la condición sociolaboral subalterna de sus padres y madres. Como explica la madre de Wendy: «En Europa, lastimosamente, mi hija no habría pasado de ser camarera». A pesar de que los menores no participen en la decisión, algunos se muestran conscientes de este límite y optan por el retorno junto a sus madres como una estrategia que les va a permitir tener mejores perspectivas, no tanto como emprendedores, sino como profesionales en un mercado laboral que demanda personas cualificadas.

\subsection{Negocio familiar, vida doméstica y reacomodos afectivos}

$\mathrm{Al}$ igual que la migración, el retorno implica un reacomodo afectivo. Muchas familias se mantuvieron separadas durante años. Al regreso, es necesario recomponer y reinventar los vínculos. Además de lo ya señalado respecto al desarraigo inicial de los hijos, destacaría otros dos hallazgos que ilustran el papel de los afectos en el retorno con negocio. El primero se refiere a las dificultades que experimentan los hombres, especialmente si migraron solos, y el segundo, a la importancia del vínculo entre madres e hijos en las familias monomarentales.

Para los varones, el negocio es una forma de reconocimiento simbólico a su regreso. Es la demostración palpable ante los otros de que su migra- 
ción ha sido exitosa. Al volver, se produce una presión para afirmar su papel como proveedores y figuras de autoridad en el hogar. Los estudios sobre reagrupación familiar desde una perspectiva de género han advertido sobre las dificultades de estos reencuentros entre cónyuges y/o hijos (HondagneuSotelo, 1994; Tacoli, 1999; Ariza, 2000; Herrera y Martínez, 2002; Pessar, 2005; Parella, 2007; Pedone, 2010; Rosas, 2011). Estar de nuevo bajo el mismo techo desencadena conflictos, y entre los más comunes está el descenso económico de la familia, producto de los bajos ingresos del varón a su regreso. El poder adquisitivo se resiente, especialmente en la primera fase, y esto también ocurre cuando se inicia un negocio. Los hombres que migraron en solitario entrevistados en este estudio, muchos de ellos con oficios en la construcción, han abierto talleres que avanzan lentamente. "Veamos si algo sacamos», comenta Emilio respecto a su taller de cerrajería. Otros, como Paúl, se lamentan de manera velada trazando una relación entre los largos años fuera, el retroceso en los ingresos y el reacomodo con su esposa tras un primer periodo de reencuentro. Su taller de soldadura no logra despegar. Para él, volver ha implicado "comenzar desde cero».

Solo, solo. Ese fue el gran error. Haberme ido solo [...] El esfuerzo que se ha hecho, ¿¿no? Mi esposa en este caso no entiende. $\mathrm{O}$ sea, parece, dice que me he ido a disfrutar, pero no es así. Es doloroso comenzar desde cero, o sea, es muy difícil. Entonces es, eso es así, no hay nada más que agregar. [...]

Con alegría en el hogar todo bien, un mes, dos meses, y ya después la dura realidad, la esposa, "que no alcanza esto...».

Algunos estudios señalan que también las mujeres ven disminuir su capacidad de gestión del hogar a la vuelta del esposo, hecho que produce discrepancias en la pareja (Parella, 2012). Resulta llamativo que las esposas de los varones que migraron solos no aceptaran participar en la entrevista. En todo caso, junto al protagonismo femenino que detectamos en este estudio, la literatura apunta de manera preliminar a una vuelta a los papeles tradicionales en la provisión y la reproducción del núcleo familiar en el retorno (Hernández et al., 2010; Herrera, 2013, Vega y Martínez, 2016; Vega, 2016) o, como veíamos arriba, a arreglos que dividen sexualmente el trabajo en el negocio familiar, con los hombres al frente del oficio y las mujeres a cargo de la familia y en la trastienda. Futuras investigaciones nos ayudarán a entender mejor estos movimientos en las relaciones de género.

En cuanto a las relaciones afectivas en el regreso de las familias monomarentales, el trabajo de campo muestra que el fuerte vínculo tejido durante la migración entre madre e hijo se actualiza en el retorno. El sostén de estas pequeñas unidades ha descansado en mayor medida sobre sus propias fortalezas: el empuje femenino en el sostenimiento, crianza y educación de los hijos, la maduración temprana de estos, la capacidad de emprender, la superación de rupturas sentimentales, los arreglos de género menos tradicionales, la posibilidad de entablar nuevas relaciones de apoyo fuera de la familia, etc. Los hijos se muestran plenamente conscientes de que la articulación entre el negocio para 
la supervivencia y sus posibilidades formativas responde a una única estrategia. Enrique, hijo de Sania, regresó a los 17 años para estudiar. Lleva tres años en Ecuador y afirma lo siguiente:

[...] solo clases, y por la noche ayudarle a mi mami. Quiero sacar la ingeniería enseguidita para meterme a trabajar y poderle ayudar a mi mami y que deje esto.

¿Quieres que deje el negocio?

Sí, es muy duro, ya la vida antes de las 6 de la mañana, y tener abierto, y estarte hasta las 11 de la noche. Yo sé que no amerita eso [...] toda la vida he estado con ella, junto a ella, no me he separado y, bueno, yo empecé pronto a entender que mi mami necesitaba ganar el dinero para ayudarme en tal cosa [...] y uno ya dice: «Bueno, tengo que hacer el esfuerzo...».

Para estas madres, el negocio de subsistencia va unido a la educación de los hijos y su futuro como profesionales, que es el motor principal para el retorno. La sensación de desarraigo, con frecuencia unida a la precariedad, se incrementa en este colectivo. Así lo explica Sania:

Yo me dedico aquí ahorita a estas cabinas y el Internet, ya que conseguir un trabajo para mí es bastante difícil, a pesar de que tengo mi preparación. Yo soy licenciada en Educación Primaria, pero yo no voy a poder conseguir, porque, según veo ahora, el presidente solamente está poniendo gente joven, ¿no? Y los viejos quedamos ahí. Entonces, la única forma de sobrevivir para mí es ponerme este pequeño negocio que tampoco me, me da para sobrevivir. [...]. No se saca ni para el alquiler. Sino que, bueno, uno ahí trata de luchar y luchar para salir adelante.

Estas unidades son las más vulnerables entre los denominados «emprendedores», las más nostálgicas respecto a la vida en España y las que se muestran más proclives a una potencial reemigración, que, para las madres, va inevitablemente unida al futuro de sus hijos.

\subsection{Politica pública y visiones (miticas) delsobre los emprendedores retornados}

Tal y como explicamos arriba, el gobierno impulsó, en el periodo del estudio, un cambio notable en la política pública dirigida al retorno que se reflejó en una modificación de la imagen de los migrantes. Un breve acercamiento a los medios de comunicación revela dicho cambio. Entre 2009 y 2013, cobra preeminencia el retorno, el impacto económico y social de la crisis a través de la reducción de las remesas, los efectos de las ejecuciones hipotecarias y la acción protectora del gobierno de la Revolución Ciudadana y los reclamos de la Plataforma de Afectados por la Hipoteca (PAH) y la Coordinadora de Ecuatorianos en España (CONADE). En general, en ese periodo, los medios enfatizaron el potencial estratégico del retornado en tanto emprendedor y el papel clave de los programas del Estado. El alcance de los mismos se inscribió en su momento en una política general, no solo dirigida a los retornados, que 
enfatizaba el emprendimiento familiar en el nuevo marco de la Economía Popular y Solidaria ${ }^{16}$. La insistencia en el carácter "productivo" del retorno en origen acaba replicando este mismo énfasis en destino (Gil, 2013). Ambos presuponen que la migración interfiere en el orden naturalizado de la nación. El migrante que retorna es un actor que puede generar sus propios mecanismos económicos de reinserción, contribuyendo, de este modo, al desarrollo del país en una coyuntura de cambio liderado por una nueva relación entre el Estado y el capital privado.

Sin duda, a muchos emprendedores les gusta reconocerse en esta imagen y verse a sí mismos como personas que "creen en su país». Tal es el caso de Lucía, con una exitosa empresa familiar de confección, o el de Leandra y Eduardo, que abrieron una academia de atletismo. Ambos proyectos pertenecen a la primera generación de beneficiarios del fondo reclutados por la propia SENAMI.

[...] eso decía mi marido: «Tú eres la que va a abrir caminos. Anda al Ecuador y yo espero, así como viniste trayéndonos a España, así también a Ecuador. Así es, con la ayuda de dios». Entonces, yo sí estoy agradecida con el presidente Correa, quien se ha preocupado de darnos esta ayuda y en especial a la mujer, que regrese con dignidad. Eso es lo que ha hecho, porque no nos ha dado pescado, no nos ha dado de comer, nos ha enseñado a pescar, para que ahora pesquemos nosotros, y eso está bien. [...]

Yo regresé en 2009, y me regresé no porque no tuviera trabajo, porque no tuviera una vida buena, regresé porque creía todavía en las posibilidades de mi país, regresé porque pienso que el Ecuador necesita gente como nosotros para salir adelante, gente que quiera trabajar y aportar un granito de arena hacia el beneficio de la juventud.

Los integrantes de este grupo, que han emprendido por oportunidad, se describen a sí mismos como sujetos cuyo capital más valioso es la actitud flexible que tuvieron que desarrollar para insertarse en un mercado laboral que no les valoraba como profesionales, sino por su disponibilidad y capacidad de adaptación. Su autoimagen, con frecuencia, se ha extrapolado, no ya al conjunto de los emprendedores, sino a la totalidad del colectivo de retornados.

Pero no todos se perciben en estos términos. Según los testimonios, la realidad de los pequeños negocios no da para tanto optimismo. En una estimación informal de la SENAMI recogida para este estudio, se estima que el 30\% de los negocios financiados enfrentan dificultades. Otras investigaciones cualitativas acerca de los llamados «emprendimientos familiares», inscritos en la Econo-

16. Ni la Encuesta Nacional de Empleo, Desempleo y Subempleo de 2014 ni los informes de la Economía Popular y Solidaria (EPS) proporcionan datos sobre el alcance de estos pequeños emprendimientos, que se disolverían en las categorías de cuentapropistas, subempleados u otros empleos inadecuados, sin que estos sean asimilables entre sí. Las cifras de pobreza en los colectivos de la EPS, 16,9 puntos mayor al resto de la Población Económicamente Activa (PEA), entre los que figuran los emprendimientos familiares, apenas sí revelan algo singular sobre estos negocios y sus protagonistas. 
mía Popular y Solidaria, revelan sus límites, no solo para quienes retornan (Enríquez, 2016). Entre los negocios examinados, cuatro han cerrado y otros tres tienen problemas. Entre estos últimos está el de Sania, a la que citábamos arriba, que no descarta volver a Madrid. Otros, como Emilia y Gustavo, en una situación menos precaria, se muestran reacios al programa, si bien, como se desprende de sus palabras, no planearon bien su negocio.

[...] un absurdo total, un desperdicio de dinero [fondos invertidos en el negocio], [...] Y, bueno, hablaron maravillas de esto. Dijeron que hay que presentar un proyecto, pero era con ideas innovadoras. Entonces, mi proyecto, yo pensé que era con ideas innovadoras, cuando aquí ya ha habido, tampoco analizaron eso [SENAMI], porque debían haber dicho: «¿Sabe qué?, señor, usted va a tener mucha competencia, ¡no!». Pero no, no, era un, para mí, una negligencia total de la SENAMI de aquel momento.

A pesar del asesoramiento y de la asistencia técnica recibida, habitualmente celebrada por los beneficiarios, las dificultades surgen, en algunos casos, por la inexperiencia, el desconocimiento de la realidad ecuatoriana y el mal diseño de las propuestas. Los retornados se quejan del papeleo exigido, así como de los impuestos que tienen que pagar. Para aquellos negocios más vulnerables, el objetivo es mantenerse a flote y la actitud de muchos de los entrevistados es, como decíamos, la de aguantar: «A ver si algo sacamos».

\section{Conclusiones}

A la luz del análisis desarrollado, la recuperación dignificada de los migrantes en el imaginario nacional por parte del gobierno de la Revolución Ciudadana, con su énfasis en el retorno con emprendimiento como camino productivo para el desarrollo, suscita dudas. La primera se refiere a la representatividad de los emprendedores y a la diversidad que este colectivo alberga. La segunda tiene que ver con la viabilidad económica de los proyectos (y las ayudas) y su peso en la estrategia global de retorno y, más allá, con el énfasis general otorgado al emprendimiento en el marco de la Economía Popular y Solidaria.

Los retornados enuncian una articulación compleja de motivos y estrategias para (y en) su regreso. En una aproximación de género y generación, que considera la composición de las familias transnacionales y sus diferencias económicas, se advierte una tipología en el retorno con emprendimiento: quienes emprenden por oportunidad y quienes lo hacen por subsistencia. Lo primero es más común entre quienes ya tenían negocios antes de migrar y quienes apostaron más claramente por un proyecto migratorio dirigido bien al retorno, bien a una estrategia de inversión a ambos lados y anticiparon la crisis en mejores circunstancias. Se trata, habitualmente, de familias tejidas en redes transnacionales tupidas que han retornado de forma escalonada y optimizando sus distintos recursos, titularidades, activos y oportunidades. Lo segundo es más corriente entre familias monomarentales, que se encuentran en una situación más vulnerable, especialmente si su plan no 
era regresar. $\mathrm{Si}$, en las primeras, las expectativas formativas y laborales de los hijos se entrecruzan y se integran en el negocio, especialmente en los liderados por mujeres, donde resulta más clara la articulación entre familia y emprendimiento, en las segundas, el futuro de hijos e hijas como profesionales en formación se separa del negocio, que, por lo general, apenas si permite sostenerse. El retorno de los varones proveedores que migraron en solitario genera, así mismo, tensiones económicas y afectivas en los hogares, ante un descenso del poder adquisitivo de la familia. Cabe, por tanto, sostener que las expectativas, las actitudes y las estrategias en relación con la reinserción en Ecuador varían de forma notable en relación con el proyecto y la trayectoria migratoria, dando lugar a distintos énfasis y estrategias económicas, sociales y familiares según el género y la generación. En ellas, los factores económicos se entrecruzan de forma compleja con otros aspectos sociales, emocionales y reproductivos.

En general, el peso que hombres y mujeres otorgan a estos pequeños negocios se articula con otras dimensiones de la vida individual y familiar. El análisis de las vivencias del retorno con emprendimiento nos insta, en todo caso, a limitar el alcance y la centralidad del mismo como experiencia migrante ejemplar, así como a examinar de forma matizada, tanto los impactos y las salidas de la crisis española, como la reincorporación a la sociedad ecuatoriana.

\section{Referencias bibliográficas}

ABAD, Luis (2006). «Las migraciones internacionales: ¿Una oportunidad para el desarrollo?». Circunstancia, IV (10), 1-26.

Acosta, Alberto (2006). La migración en el Ecuador: Oportunidades y amenazas. Quito: Corporación Editora Nacional.

- (2013). «El retorno del Estado». En: Acosta, Alberto y Martín, Fernando (eds.). Situación económica ambiental del Ecuador en un entorno de crisis internacional. Quito: FLACSO Ecuador.

Agarwal, Bina (1997). "Bargaining" and gender relations: Within and beyond the household». Feminist Economics [en línea], 3 (1), 1-51. $<$ http://dx.doi.org/10.1080/135457097338799>.

Agustín, Laura (2007). Sex at the Margins: Migration, Labour Markets and the Rescue Industry. Londres: Zed Books.

Anderson, Bridget (2006). A very private business: Migration and domestic work [en línea]. <http://www.compas.ox.ac.uk/fileadmin/files/Publications/working_papers/ WP_2006/WP0628_Anderson.pdf>.

Anthias, Floya y Yuval Davis, Nina (1992). Racialised Boundaries: Race, Nation, Gender, Class and the Anti-racist Struggle. Londres: Routledge.

Arango, Joaquín (2003) «La explicación teórica de las migraciones: Luz y sombra». Migración y Desarrollo, 1 (octubre), 1-30.

Arango, Joaquín; Moya, David y Oliver, Josep (eds.) (2014). Inmigración y emigración: mitos y realidades: Anuario de Inmigración en España. Barcelona: Bellaterra.

Ariza, Marina (2000). Ya no soy la que dejé atrás: Mujeres migrantes en República Dominicana. México: UNAM / Instituto de Investigaciones Sociales / Editorial Plaza y Valdés. 
Arjona, Ángeles y ChecA, Juan Carlos (2007). «Factores explicativos de la segregación residencial de los inmigrantes en Almería». Revista Internacional de Sociología [en línea], 48, 173-200. <http://dx.doi.org/10.3989/ris.2007.i48.73>.

Arroyo, Jesús (2004). «Efectos económicos de la migración mexicana a Estados Unidos». Congreso Internacional sobre Migración y Desarrollo. México: Colmex, D. F.

Aysa-Lastra, María y Cachón, Lorenzo (2013). «Determinantes de la movilidad ocupacional segmentada de los inmigrantes no comunitarios en España». Revista Internacional de Sociología [en línea], 71 (2), 383-413. $<$ http://dx.doi.org/10.5477/cis/reis.144.23>.

BAKKer, Matt (2006). "Remittances-to-development": Collaboration, Contestation or What?». II Coloquio Internacional sobre Migración y Desarrollo. México: Red Internacional de Migración y Desarrollo.

Benería, Lourdes (2008). "De la "armonía” a los "conflictos cooperativos": La contribución de Amartya Sen a la teoría de la unidad doméstica». Araucaria, 10 (20), s/p.

Boccagni, Paolo y Lagomarsino, Francesca (2011). "Migration and the global crisis: New prospects for return? The case of Ecuatorians in Europe». Bulletin of Latin American Research [en línea], 30 (3), 282-297. <http://dx.doi.org/10.1111/j.1470-9856.2010.00494.x>.

Canales, Alejandro (2006). «Migración, remesas y desarrollo: Mitos y realidades», comentarios al texto de Donald Terry «Las remesas como instrumento de desarrollo». Encuentro Iberoamericano sobre Migración y Desarrollo. Secretaría General Iberoamericana. Madrid, 18 y 19 de julio.

Cassarino, Jean-Pierre (2004). «Theorising Return Migration: The Conceptual Approach to Return Migrants Revisited». IJMS: International Journal on Multicultural Societies, 6 (2), 253-279.

Cavalcanti, Leonardo y Boggio, Karina (2004). "Una presencia ausente en espacios transnacionales: Un análisis sobre la cuestión del retorno, a partir del cotidiano de uruguayos y brasileños en España». IV Congreso sobre la Inmigración en España: Ciudadanía y Participación. Gerona.

Cavalcanti, Leonardo y Parella, Sònia (2013). «El retorno desde una perspectiva transnacional». Revista Interdisciplinaria de Movilidad Humana-REMHU [en línea], 41, 9-20. <http://dx.doi.org/10.1590/s1980-85852013000200002>.

Centro de Derechos Economicos y Sociales-CDES (2013). «Pan C: Redistribución de la riqueza para no explotar el Yasuní y salvaguardar a los indígenas aislados", Linea de Fuego. <https://lalineadefuego.info/2013/09/25/plan-c-redistribucion-de-la-riqueza-para-no-explotar-el-yasuni-y-salvaguardar-a-los-indigenasaislados-por-cdes/>.

Colau, Ada y Alemany, Adrià (2012). Vidas hipotecadas: De la burbuja inmobiliaria al derecho a la vivienda. Barcelona: Cuadrilátero.

Colectivo IOÉ (2011). «Los impactos de la crisis en la población inmigrante», Colectivo Ioé, 1-204. <http://www.colectivoioe.org/uploads/0bae582aa3b0842a9eaf50 cde16f4f97d9527bcb.pdf>

Colectivo IOÉ (2013). «La población inmigrada ante la crisis: ¿Mirando hacia otro lado?». Boletín Ecos, 4, 1-10.

Coloma, Soledad (2011). ¿Qué tan distinto es el sujeto migrante calificado?: Itinerarios migratorios y capital social entre migrantes calificados ecuatorianos en Estados Unidos. Quito: FLACSO-Ecuador. Tesis de maestría. 
Coraggio, José Luis (2012). Conocimiento y politicas públicas de economía social y solidaria: Problemas y propuestas. Quito: IAEN.

CorTÉs, Almudena (2009). «La migración ecuatoriana en el codesarrollo: ¿Hacia una gobernanza transnacional?». En: CorTÉs, Almudena y Torres, Alicia (coords.). Codesarrollo en los Andes: Contextos y actores para una acción transnacional. Ecuador: FLACSO / Instituto Universitario de Migraciones, Etnicidad y Desarrollo (IMEDES). Madrid: Universidad Autónoma de Madrid.

- (2010). «La reinvención del nexo migración y desarrollo desde el sur de Europa: El caso de Ecuador y España». Relaciones Internacionales, 14, 39-59.

- (2011). "Gobernando a distancia desde el sur de Europa: La migración ecuatoriana y el codesarrollo como campos sociales de acción transnacional». Oñati Socio-legal Series, 1, 4-25.

De Haas, Hein y Fonkema, Tineke (2011). «The effects of integration and transnational ties on international return migration intentions». Demographic Research [en línea], 25, 755-782. <http://dx.doi.org/10.4054/demres.2011.25.24>.

Duque, Guido y Genta Rossi, Natalia (2009). «Crisis y migración: ¿El retorno esperado o búsqueda de alternativas?». Andina Migrante, 5, 2-10.

Durand, Jorge (2004). «Ensayo crítico sobre la emigración de retorno: El principio del rendimiento decreciente». Cuadernos Geográficos, 35, 103-116.

Eguiguren, María Mercedes (2011). Sujeto migrante, crisis y tutela estatal: Construcción de la migración y modos de intervención desde el Estado ecuatoriano. Quito: FLACSO Ecuador. Tesis de maestría en Ciencias Sociales con mención en Sociología.

ENRÍQUeZ, Maria José (2016). Los procesos de empoderamiento de las mujeres que se asocian para superar la pobreza: Caso Red de Economía Popular y Solidaria-REDEPS. Quito: FLACSO Ecuador. Tesis de maestría en Ciencias Sociales con mención en Género y Desarrollo.

Escobar, Arturo (1996). La invención del Tercer Mundo: Construcción y deconstrucción del desarrollo. Bogotá: Norma.

- (2005). «Economics and the Space of Modernity: Tales of Market, Production and Labor». Cultural Studies [en línea], 19 (2), 139-175. <http://dx.doi.org/10.1080/09502380500077714>.

Fernández, María Patricia (1983). «Mexican Border Industrialization, Female Labor Force Participation and Migration». Women, Men, and the International Division of Labor, 42, 565-576.

Fischer, Peter; Martin, Reiner y Straubhaar, Thomas (1997). «Interdependences between Development and Migration». En: Hammar, Tomas; Brochmann, Grete; TAMAS, Kristof $y$ FAIst, Thomas (eds.). International Migration, Immobility and Development: Multidisciplinary Perspectives. Oxford: Berg.

García, Rodolfo (2003). La transferencia y uso de las remesas: Proyectos productivos y de ahorro. México: Zacatecas / CEPAL / Sin Fronteras / UAZ.

GIL, Sandra (2010). Las argucias de la integración: Politicas migratorias, construcción nacional y cuestión social. Madrid: IEPALA.

- (2013). «Buscando la nación por el camino del retorno: Reflexiones sobre las políticas y el estudio del retorno en los actuales contextos de emigración/inmigración». En: Pedone, Claudia y GiL, Sandra. Politicas públicas, migración familiar y retorno de la población migrante latinoamericana en Cataluña: Una perspectiva transnacional. Barcelona: Consorci Institut d'Infancia i Món Urbà (CIIMU).

GoldrIng, Luin (2001). «Disaggregating Transnational Social Spaces: Gender, Place 
and Citizenship in Mexico-US Transnational Spaces». En: Pries, Ludger. New Transnational Social Spaces: International migration and transnational companies in the early twenty-first century. Londres: Routledge.

Gómez, Emilio; Tornos, Andrés y Colectivo IOÉ (2007). Ecuatorianos en España: Una aproximación sociológica. Madrid: Ministerio de Trabajo y Asuntos Sociales.

Grasmuck, Sherri y Pessar, Patricia (1991). Between Two Islands: Dominican Internacional Migration. Berkeley: University of California Press.

Guarnizo, Luis Eduardo (1996). "Going Home”: Class, Gender, and Household Transformation Among Dominican Return Migrants?». Center for Migration Studies special issues [en línea], 13 (4), 13-60.

<http://dx.doi.org/10.1111/j.2050-411x.1996.tb00154.x>.

Harris, John y Todaro, Michael (1970). «Migration, unemployment and development: A two-sector analysis». American Economic Review, 60 (1), 126-142.

Hernández, Kattya; Maldonado, Mónica y Calderon, Jefferson (2012). Entre crisis y crisis experiencias de emigración y retorno: El caso de los barrios populares de noroccidente de Quito. Quito: Abya-Yala.

Herrera, Gioconda (2006). «Precarización del trabajo, crisis de reproducción social y migración femenina: Ecuatorianas en España y Estados Unidos». En: Herrera, Gioconda (coord.). La persistencia de la desigualdad: Género, trabajo y pobreza en América Latina. Quito: FLACSO / CONAMU / Secretaría Técnica Frente Social.

- (2013). "Lejos de tus pupilas»: Familias transnacionales, cuidados y desigualdad social en Ecuador [en línea]. Quito: FLACSO Ecuador / ONU Mujeres. $<$ http://dx.doi.org/10.17141/iconos.47.2013.855>.

Herrera, Gioconda y Carrillo, María Cristina (2009). «Transformaciones familiares en la experiencia migratoria ecuatoriana: Una mirada desde los contextos de salida». Mélanges de la Casa de Velázquez, 39 (1), 97-114.

Herrera, Gioconda y Martínez, Alexandra (2002). «Género y migración en la región Sur». Informe de investigación. Quito: FLACSO Ecuador.

Herrera, Gioconda; Moncayo, María Isabel y Escobar, Alexandra (2012). Perfil Migratorio del Ecuador 2011. Quito: Organización Internacional para las Migraciones (OIM).

Herrera, Gioconda y Vega, Cristina (coords.) (2013). El retorno a Ecuador desde España: Estrategias económicas, socio-familiares y afectivas para una integración transnacional. Quito: FLACSO Ecuador. Informe.

Hochschild, Arlie Russell (2000). "Global Care Chains and Emotional Surplus Value». En: Hutton, Will y Giddens, Anthony (eds.). On The Edge: Living with Global Capitalism. Londres: Jonathan Cape.

Hondagneu-Sotelo, P. (1994). Gendered transitions: Mexican experiences of immigration. Berkeley: University of California Press.

- (1999). "Introduction: Gender and Contemporary U. S. Immigration». American Behavioral Scientist [en línea], 42, 565-576. <http://dx.doi.org/10.1177/00027649921954363>.

Hondagneu, Pierrette y Cranford, Cynthia (1999). "Gender and migration». En: Saltzman Chaffetz, Janet (ed.). Handbook of the sociology gender. Nueva York: Kluwer Academic / Plenum Publishers.

Kofman, Eleonore (1999). «Female "Birds of passage" a Decade Later: Gender and Imigration in the European Union». International Migration Review [en línea], 32 (2), 269-299. <http://dx.doi.org/10.2307/2547698>. 
Kofman, Eleonore; Phizacklea, Annie; Raghuram, Parvati y Sales, Rosemary (eds.) (2000). Gender and international migration in Europe. Londres: Routledge.

Kunz, Rahel (2006). "The "social cost" of migration and remittances: Recovering the silenced voices of the global remittance trend». II Coloquio Internacional sobre Migración y Desarrollo: Red Internacional de Migración y Desarrollo [en línea]. México. <http://estudiosdeldesarrollo.net/coloquio2006/14698.pdf>.

Lacomba, Joan (2004). Migraciones y desarrollo en Marruecos. Madrid: Instituto Universitario de Desarrollo y Cooperación / Catarata.

Levitt, Peggy y Glick Schiller, Nina (2004). «Perspectivas internacionales sobre migración: Conceptuar la simultaneidad». Migración y Desarrollo, 3, 60-91.

LevitT, Peggy y Sorensen, Ninna (2004). «The transnational turn in migration studies». Global Migration Perspectives, 6, 2-13.

MArTín, Emma (2012). «Estrategias migratorias de las mujeres ecuatorianas en Sevilla: Acumulación de capital social en tiempos de crisis». Migraciones Internacionales, $6(4), 107-138$.

Martínez, Raquel (2011). «La reorganización de los cuidados familiares en un contexto de migración internacional». Cuadernos de Relaciones Laborales [en línea], 29 (1), 93-123. <http://dx.doi.org/10.5209/rev_crla.2011.v29.n1.4>.

- (2015). «Gendered motivations of migration retur to Bolivia From Spain». Journal of Immigrants and Refugee Studies, 12 (4), 401-418.

Massey, Douglas; Alarcón, Rafael; Duran, Jorge y González, Humberto (1987). Return to Aztlan: The Social Process of Internacional Migration from Western Mexico. Berkeley: University of California.

Moncayo, María Isabel (2011a). Migración y retorno en el Ecuador: Entre el discurso político y la política de gobierno. Quito: FLACSO Ecuador.

- (2011b). «Políticas de retorno en América Latina: Miradas cruzadas». Andina Migrante, 10, 2-10.

Morokvasic, Mirjana (1984). «Birds of passage are also women». Women in Migration [en línea], 18 (4), 886-907. <http://dx.doi.org/10.2307/2546066>.

Navarro, Vicenç; Torres, Juan y Garzón, Alberto (2011). Hay alternativas: Propuestas para crear empleo y bienestar social en España. Madrid: Sequitur.

Newland, Kathleen y Tanaka, Hiroyuki (2010). Mobilizing diaspora entrepreneurship for development. Washington, D. C.: Migration Policy Institute.

Olesen, Henrik (2002). «Migration, return and development: An institutional perspective». International Migration [en línea], 40 (5), 125-150. <http://dx.doi.org/10.1111/1468-2435.00214>.

Oso, Laura (2007). «Inmigracion, desarrollo y estrategias de movilidad social». Revista Española de Desarrollo y Cooperación, 19, 107-120.

- (2009). «Familia, empresa y movilidad ocupacional: Mujeres latinoamericanas en España». Mélanges de la Casa de Velázquez, 39 (1), 57-74.

- (2011). «Plata y/o amor: Remesas, acumulación de activos y movilidad social de las familias de migrantes ecuatorianos». En: GinieniewiCZ, J. (coord.). La migración latinoamericana a España: Una mirada desde el modelo de acumulación de activos. Quito: FLACSO, 129-150.

Oso, Laura y Catarino, Christine (2009). «Género, feminización de las migraciones e inserción al mercado de trabajo en España y Portugal». En: Grupo InTERDisCi- 
plinario de Investigadores Migrantes (eds.). Familias, niños, niñas y jóvenes migrantes: Rompiendo estereotipos. Madrid: Iepala.

Parella, Sònia (2005). Mujer, inmigrante y trabajadora: La triple discriminación. Barcelona: Anthropos.

- (2007). "Los vínculos afectivos y de cuidado en las familias transnacionales: Migrantes ecuatorianos y peruanos en España». Migraciones Internacionales, 4 (2), $39-76$.

- (2012). «Familia transnacional y redefinición de los roles de género: El caso de la migración boliviana en España». Papers: Revista de Sociologia, 97 (3), 661-684. <http://dx.doi.org/10.5565/rev/papers/v97n3.454>

- (2013). «Bolivian Migrants in Spain: Transnational Families from a Gender Perspective». En: The International Handbook on Gender, Migration and Transnationalism. Coruña: Universidade da Coruña.

PARella, Sònia y Oso, Laura (2012). «Inmigración, género y mercado de trabajo: Una panorámica de la investigación sobre la inserción laboral de las mujeres inmigrantes». Cuadernos de Relaciones Laborales, 30 (1), 11-44.

Parella, Sònia y Petroff, Alisa (2014). «Migración de retorno en España: Salidas de inmigrantes y programas de retorno en un contexto de crisis». En: Arango, Joaquín. Anuario de la inmigración en España: Inmigración y emigración: mitos y realidades. Barcelona: CIDOB.

Parella, Sònia; Petroff, Alisa y Serradell, Olga (2009). Una aproximación a las políticas de retorno voluntario de migrantes: El caso de la migración boliviana residente en España a partir de la crisis 2008/2009 [en línea]. <www.fes-web.org/uploads/ files/modules/.../723.docx>.

- (2014). «Programas de retorno voluntario en Bolivia y España en contextos de crisis». Revista CIDOB d'Afers Internacionals, 106-107, 1133-6595.

Parreñas, Rachel (2005). «Long distance intimacy: Class, gender and intergenerational relations between mothers and children in Filipino transnational families». Global Networks [en línea], 5 (4), 317-336. <http://dx.doi.org/10.1111/j.1471-0374.2005.00122.x>.

Pedone, Claudia (2006). Tu siempre jalas a los tuyos: Estrategias migratorias y poder. Quito: Abya-Yala.

- (2010). «Más allá de los estereotipos: Desafíos en torno al estudio de las familias migrantes». En: Grupo Interdisciplinario de Investigador@s Migrantes (coord.). Familias, niños, niñas y jóvenes migrantes: Rompiendo estereotipos. Madrid: IEPALA.

PedreÑo, Andrés (2005). «La condición inmigrante: Exploraciones e investigaciones desde la región de Murcia». Revista Andaluza de Ciencias Sociales, 5, 114-116.

Pérez Orozco, Amaia (2007). «Migration and development». Working Paper 3. Gender, Migration and Development. Santo Domingo: UN-INSTRAW.

Peris-Mecheta, Juan; López, Susana y Manaset, Erika (2011). "¿Retornar o quedarse?: Dilemas sobre la permanencia y el retorno en la población ecuatoriana en España». IV Congreso de la Red Internacional de Migración y Desarrollo. Crisis Global y Estrategias Migratorias: Hacia la redefinición de las politicas de movilidad. Quito: FLACSO Ecuador.

Pessar, Patricia (2005). Women, Gender, and International Migration across and Beyond the Americas: Inequalities and Limited Empowerment. México, D. F.: Expert Group Meeting on International Migration and Development in Latin America and The Caribean.

Phizacklea, Annie (ed.) (1983). One Way Ticket: Migration and Female Labour. Londres: Routledge. 
Portes, Alejandro y Walton, John (1981). Labor, Class, and the International System. Nueva York: Academic Press.

Ramírez, Franklin y Ramírez, Jacques (2004). La estampida migratoria. Quito: AbyaYala.

RAMÍREZ, Jacques (2013). La política migratoria en Ecuador: Rupturas, tensiones, continuidades y desafíos. Quito: IAEN.

Riaño, Yvonne (2011): "He’s the Swiss Citizen, I'm the Foreign Spouse": Transnational Marriages and the Impact of Family-Related Migration Policies on Social Integration and Gender Relations». En: Kofman, Eleonore; Kohli, Martin; Kraler, Albert y Schmoll, Camille (eds.). Gender, Generations, and the Family in International Migration. IMISCOE Research. Amsterdam: Amsterdam University Press.

Ribas-Mateos, Natalia y Oso, Laura (eds.) (2013). «An introduction to a global and development perspective: A focus on gender, migration and transnationalism». En: Oso, Laura y Ribas-Mateos, Natalia. The International Handbook on Gender, Migration and Transnationalism: Global and Development Perspectives. Cheltenham: Edward Elgar Publishers.

Roncken, Theo y Torre, Leonardo de la (2009). Potencial para el emprendimiento microempresarial de retorno en localidades bolivianas de alta migración hacia España. FIE, Fundación Crea Empresa, BID. Mimeo.

Rosas, Carolina (2011). «De nuevo bajo el mismo techo: Desafíos y reconfiguraciones en los procesos de reunificación de parejas migrantes». Mora, 18 (2), s/n.

Rowan, Jaron (2010). Emprendizajes en cultura: Discursos, instituciones y contradicciones de la empresarialidad cultural. Madrid: Traficantes de Sueños.

Salazar Parreñas, Rhacel (2005). Children of Global Migration: Transnational Families and Gendered Woes. Standford: Standford University Press.

SANZ, Jesús (2009). "La lógica del retorno frente a la lógica de la permanencia de la migración ecuatoriana en España: Reproducción social y estrategias económicas para la movilidad social en el contexto migratorio». En: CAMACHo, Gloria y HerNÁNDEZ, Kattya (eds.). Miradas transnacionales: Visiones de la migración ecuatoriana desde España y Ecuador. Quito: SEPLAES.

SAssen, Saskia (1988). The Mobility of Labor and Capital: A Study in International Investment and Labor. Cambridge: Cambridge University Press.

- (2003). Contrageografías de la globalización. Madrid: Traficantes de Sueños.

SAYAD, Abdelmalek (2000). "O retorno: Elemento constitutivo da condição do migrante». Travessia, 13, 7-32.

Schramm, Christian (2011). "Retorno y reinserción de migrantes ecuatorianos: La importancia de las redes sociales transnacionales». Revista d'Afers Internacionals, 93-94, 241-260.

SJAASTAD, Larry (1962). "The costs and returns of human migration». Journal of Political Economy [en línea], 70 (5), 80-93. $<$ http://dx.doi.org/10.1086/258726>.

STARK, Oded (1984). "Rural-urban migration in LDCs: A relative deprivation approach». Economic Development Change [en línea], 32 (3), 475-486. <http://dx.doi.org/10.1086/451401>.

STARK, Oded y BloOM, David (1985). "The new economics of labor migration». American Economic Review, 75 (2), 173-178.

SuÁrez, Maka (2014). «Movimientos sociales y Buen Vivir: Ecuatorianos en la lucha por la vivienda en la plataforma de afectados por la hipoteca (PAH)». Revista de Antropología Experimental, 6 (14), 71-89. 
SuÁRez Navaz, Liliana (2004). «Transformaciones de género en el campo transnacional: El caso de las mujeres inmigrantes en España». La Ventana, 20, 293-331.

TACOLI, Cecilia (1999). "International Migration and the restructuring of gender asymmetries: Continuity and change among Filipino labour migrants in Rome». International Migration Review [en línea], 33 (3), 658-682. $<$ http://dx.doi.org/10.2307/2547530>.

Todaro, Michael P. (1969). "A Model of Labor Migration and Urban Unemployment in Less Developed Countries». The American Economic Review, 59 (1), $138-148$.

Tovar, Luis Miguel y Victoria, María Teresa (2013). «Migración internacional de retorno y emprendimiento: Revisión de la literatura». Revista de Economía Institucional, 15 (29), 41-65.

VEGA, Cristina (1999). «Extranjeras en la ciudad: Itinerarios de mujeres okupas e inmigrantes en el barrio de Lavapiés (Madrid)». En: Bernárdez, Asunción. Perdidas en el espacio: Formas de ocupar, recorrer y representar los lugares. Madrid: Huerga y Fierro.

Vega, Cristina (2016). "Complejizando el "Retorno Productivo": Mujeres y hombres ante el regreso a Ecuador desde España». Amerique Latine. Histoire \& Memoire. Número especial: «Mujeres y migraciones en Las Américas», 31 <http://alhim. revues.org/5498>

Vega, Cristina; Gómez, Carmen y Correa, Ahmed (2016a) «Circularidad migratoria entre Ecuador y España: Transformación educativa y estrategias de movilidad». Migraciones, 39, 183-210.

Vega, Cristina; Gómez, Carmen y Monteros, Silvina (2016b). Jóvenes ecuatorianos, movilidad y educación superior en España y Ecuador: Trayectorias educativas desiguales en tiempos de crisis. Quito: FLACSO Ecuador.

Vega, Cristina y Martínez Buján, Raquel (2016). «Las migraciones de retorno de la población ecuatoriana y boliviana desde España: Motivaciones y experiencias de reinsercion desde una perspectiva de género y generación. Investigaciones Feministas. Monográfico: «Género, Migraciones y Trabajo: Modalidades de producción y reproducción social en la Europa del Sur». 7 (1), 265-287. 